\title{
The Cloud Feedback Model Intercomparison Project (CFMIP) contribution to CMIP6
}

\author{
Mark J. Webb ${ }^{1}$, Timothy Andrews ${ }^{1}$, Alejandro Bodas-Salcedo ${ }^{1}$, Sandrine Bony ${ }^{2}$, Christopher S. Bretherton ${ }^{3}$, \\ Robin Chadwick $^{1}$, Hélène Chepfer ${ }^{2}$, Hervé Douville ${ }^{4}$, Peter Good ${ }^{1}$, Jennifer E. Kay ${ }^{5}$, Stephen A. Klein ${ }^{6}$, \\ Roger Marchand ${ }^{3}$, Brian Medeiros ${ }^{7}$, A. Pier Siebesma ${ }^{8}$, Christopher B. Skinner ${ }^{9}$, Bjorn Stevens $^{10}$, \\ George Tselioudis $^{11}$, Yoko Tsushima ${ }^{1}$, and Masahiro Watanabe ${ }^{12}$ \\ ${ }^{1}$ Met Office Hadley Centre, Exeter, UK \\ ${ }^{2}$ LMD/IPSL, CNRS, Université Pierre and Marie Curie, Paris, France \\ ${ }^{3}$ University of Washington, Seattle, USA \\ ${ }^{4}$ Centre National de Recherches Météorologiques, Toulouse, France \\ ${ }^{5}$ University of Colorado at Boulder, Boulder, USA \\ ${ }^{6}$ Lawrence Livermore National Laboratory, Livermore, USA \\ ${ }^{7}$ National Center for Atmospheric Research, Boulder, USA \\ ${ }^{8}$ Royal Netherlands Meteorological Institute, De Bilt, The Netherlands \\ ${ }^{9}$ University of Michigan, Ann Arbor, USA \\ ${ }^{10}$ Max Planck Institute for Meteorology, Hamburg, Germany \\ ${ }^{11}$ NASA Goddard Institute for Space Studies, New York, USA \\ ${ }^{12}$ Atmosphere and Ocean Research Institute, Tokyo, Japan
}

Correspondence to: Mark J. Webb (mark.webb@metoffice.gov.uk)

Received: 30 March 2016 - Published in Geosci. Model Dev. Discuss.: 12 May 2016

Revised: 28 October 2016 - Accepted: 31 October 2016 - Published: 25 January 2017

\begin{abstract}
The primary objective of CFMIP is to inform future assessments of cloud feedbacks through improved understanding of cloud-climate feedback mechanisms and better evaluation of cloud processes and cloud feedbacks in climate models. However, the CFMIP approach is also increasingly being used to understand other aspects of climate change, and so a second objective has now been introduced, to improve understanding of circulation, regional-scale precipitation, and non-linear changes. CFMIP is supporting ongoing model inter-comparison activities by coordinating a hierarchy of targeted experiments for CMIP6, along with a set of cloud-related output diagnostics. CFMIP contributes primarily to addressing the CMIP6 questions "How does the Earth system respond to forcing?" and "What are the origins and consequences of systematic model biases?" and supports the activities of the WCRP Grand Challenge on Clouds, Circulation and Climate Sensitivity.

A compact set of Tier 1 experiments is proposed for CMIP6 to address this question: (1) what are the physical
\end{abstract}

mechanisms underlying the range of cloud feedbacks and cloud adjustments predicted by climate models, and which models have the most credible cloud feedbacks? Additional Tier 2 experiments are proposed to address the following questions. (2) Are cloud feedbacks consistent for climate cooling and warming, and if not, why? (3) How do cloudradiative effects impact the structure, the strength and the variability of the general atmospheric circulation in present and future climates? (4) How do responses in the climate system due to changes in solar forcing differ from changes due to $\mathrm{CO}_{2}$, and is the response sensitive to the sign of the forcing? (5) To what extent is regional climate change per $\mathrm{CO}_{2}$ doubling state-dependent (non-linear), and why? (6) Are climate feedbacks during the 20th century different to those acting on long-term climate change and climate sensitivity? (7) How do regional climate responses (e.g. in precipitation) and their uncertainties in coupled models arise from the combination of different aspects of $\mathrm{CO}_{2}$ forcing and sea surface warming? 
CFMIP also proposes a number of additional model outputs in the CMIP DECK, CMIP6 Historical and CMIP6 CFMIP experiments, including COSP simulator outputs and process diagnostics to address the following questions.

1. How well do clouds and other relevant variables simulated by models agree with observations?

2. What physical processes and mechanisms are important for a credible simulation of clouds, cloud feedbacks and cloud adjustments in climate models?

3. Which models have the most credible representations of processes relevant to the simulation of clouds?

4. How do clouds and their changes interact with other elements of the climate system?

\section{Introduction}

Inter-model differences in cloud feedbacks continue to be the largest source of uncertainty in predictions of equilibrium climate sensitivity (Boucher et al., 2013). Although the ranges of cloud feedbacks and climate sensitivity from comprehensive climate models have not reduced in recent years, considerable progress has been made in understanding (a) which types of clouds contribute most to this spread (e.g. Bony and Dufresne, 2005; Webb et al., 2006; Zelinka et al., 2013), (b) the role of cloud adjustments in climate sensitivity (e.g. Gregory and Webb, 2008; Andrews and Forster, 2008; Kamae and Watanabe, 2012; Zelinka et al., 2013), (c) the processes and mechanisms which are (and are not) implicated in cloud feedbacks, both in fine-resolution models (e.g. Rieck et al., 2012; Bretherton et al., 2015) and in comprehensive climate models (e.g. Brient and Bony, 2012; Sherwood et al., 2014; Zhao, 2014; Webb et al., 2015b), (d) the inconstancy of cloud feedbacks and effective climate sensitivity (e.g. Senior and Mitchell, 2000; Williams et al., 2008; Andrews et al., 2012; Geoffroy et al., 2013; Armour et al., 2013; Gregory and Andrews, 2016) and (e) the extent to which models with stronger or weaker cloud feedbacks or climate sensitivities agree with observations (e.g. Fasullo and Trenberth, 2012; Su et al., 2014; Qu et al., 2014; Sherwood et al., 2014; Myers and Norris, 2016). Additionally, our ability to evaluate model clouds using satellite data has benefited from the increasing use of satellite simulators. This approach, first introduced by Yu et al. (1996) for use with data from the International Satellite Cloud Climatology Project (ISCCP), attempts to reproduce what a satellite would observe given the model state. Such approaches enable more quantitative comparisons to the satellite record (e.g. Yu et al., 1996; Klein and Jakob, 1999; Webb et al., 2001; Bodas-Salcedo et al., 2008; Cesana and Chepfer, 2013). Much of our improved understanding in these areas would have been impossible without the continuing investment of the scientific community in successive phases of the Coupled Model Intercomparison Project (CMIP) and its co-evolution in more recent years with the Cloud Feedback Model Intercomparison Project (CFMIP).

CFMIP started in 2003 and its first phase (CFMIP-1) organized an intercomparison based on perpetual July SST forced Cess style $+2 \mathrm{~K}$ experiments and $2 \times \mathrm{CO}_{2}$ equilibrium mixed-layer model experiments containing an ISCCP simulator in parallel with CMIP3 (McAvaney and Le Treut, 2003). CFMIP-1 had a substantial impact on the evaluation of clouds in models and on the identification of low-level cloud feedbacks as the primary cause of inter-model spread in cloud feedback, which featured prominently in the fourth and fifth IPCC assessments (Randall et al., 2007; Boucher et al., 2013).

The subsequent objective of CFMIP-2 was to inform improved assessments of climate change cloud feedbacks by providing better tools to support evaluation of clouds simulated by climate models and understanding of cloud-climate feedback processes. CFMIP-2 organized further experiments as part of CMIP5 (Bony et al., 2011; Taylor et al., 2012), introducing seasonally varying SST perturbation experiments for the first time, as well as fixed SST $\mathrm{CO}_{2}$ forcing experiments to examine cloud adjustments. CFMIP-2 also introduced idealized "aquaplanet" experiments into the CMIP family of experiments. These experiments were motivated by extensive research in the framework of the aquaplanet experiment (Neale and Hoskins, 2000; Blackburn and Hoskins, 2013) and the particular finding, based on a small subset of models, that the global mean cloud feedback of more realistic model configurations could be reproduced, and more easily investigated, using the much simpler aquaplanet configuration (Medeiros et al., 2008). CFMIP-2 proposed the inclusion of the abrupt $\mathrm{CO}_{2}$ quadrupling AOGCM (atmosphere-ocean general circulation model) experiment in the core experiment set of CMIP5, based on the approach of Gregory et al. (2004) which subsequently formed the basis for equilibrium climate sensitivity estimates from AOGCMs (Andrews et al., 2012). Additionally, CFMIP-2 introduced satellite simulators to CMIP via the CFMIP Observation Simulator Package (COSP, Bodas-Salcedo et al., 2011): not only the ISCCP simulator, but also additional simulators to facilitate the quantitative evaluation clouds using a new generation of active radars and lidars in space. CFMIP-2 also introduced into CMIP5 process diagnostics such as temperature and humidity budget tendency terms and high-frequency "cfSites" outputs at 120 locations around the globe. In an effort less directly connected to CMIP, CFMIP organized a joint project with the GEWEX Global Atmospheric System Study (GASS) called CGILS (the CFMIP-GASS Intercomparison of LES and SCMs) to develop cloud feedback intercomparison cases to assess the physical credibility of cloud feedbacks in climate models by comparing single-column model (SCM) versions of general circulation models (GCMs) with high-resolution large eddy simulation (LES) models. CFMIP-2 also devel- 
oped the CFMIP-OBS data portal and the CFMIP Diagnostic Codes Catalogue. For more details, and for a full list of CFMIP-related publications, please refer to the CFMIP website (http://www.earthsystemcog.org/projects/cfmip).

Studies arising from CFMIP-2 include numerous singleand multi-model evaluation studies which use COSP to make quantitative and fair comparisons with a range of satellite products (e.g. Kay et al., 2012; Franklin et al., 2013; Klein et al., 2013; Lin et al., 2014; Chepfer et al., 2014). COSP has also enabled studies attributing cloud feedbacks and cloud adjustments to different cloud types (e.g. Zelinka et al., 2013, 2014; Tsushima et al., 2016). CFMIP-2 additionally enabled the finding that idealized "aquaplanet" experiments without land, seasonal cycles or Walker circulations are able to reproduce the essential differences between models' global cloud feedbacks and cloud adjustments in a substantial ensemble of models (Ringer et al., 2014; Medeiros et al., 2015). Process outputs from CFMIP have also been used to develop and test physical mechanisms proposed to explain and constrain inter-model spread in cloud feedbacks in the CMIP5 models (e.g. Sherwood et al., 2014; Brient et al., 2015; Webb et al., 2015a; Nuijens et al., 2015a, b; Dal Gesso at al., 2015). CGILS has demonstrated a consensus in the responses of LES models to climate forcings and identified shortcomings in the physical representations of cloud feedbacks in climate models (e.g. Blossey et al., 2013; Zhang et al., 2013; Dal Gesso at al., 2015). The CFMIP experiments have additionally formed the basis for coordinated experiments to explore the impact of cloud-radiative effects on the circulation (Stevens et al., 2012; Fermepin and Bony, 2014; Crueger and Stevens, 2015; Li et al., 2015; Harrop and Hartmann, 2016), the impact of parametrized convection on cloud feedback (Webb et al., 2015b) and the mechanisms of negative shortwave cloud feedback in mid to high latitudes (Ceppi et al., 2015). Additionally, the CFMIP experiments have, due to their idealized nature, proven useful in a number of studies not directly related to clouds, instead analysing the responses of regional precipitation and circulation patterns to $\mathrm{CO}_{2}$ forcing and climate change (e.g. Bony et al., 2013; Chadwick et al., 2014; He and Soden, 2015; Oueslati et al., 2016). Studies using CFMIP-2 outputs from CMIP5 remain ongoing and further results are expected to feed into future assessments of the representation of clouds and cloud feedbacks in climate models.

The primary objective of CFMIP is to inform future assessments of cloud feedbacks through improved understanding of cloud-climate feedback mechanisms and better evaluation of cloud processes and cloud feedbacks in climate models. However, the CFMIP approach is also increasingly being used to understand other aspects of climate change, and so a second objective has been introduced, to improve understanding of circulation, regional-scale precipitation, and nonlinear changes. This involves bringing climate modelling, observational and process modelling communities closer together and providing better tools and community support for evaluation of clouds and cloud feedbacks simulated by climate models and for understanding of the mechanisms underlying them. This is achieved by

- coordinating model inter-comparison activities which include experimental design as well as specification of model output diagnostics to support quantitative evaluation of modelled clouds with observations (e.g. COSP) and in situ measurements (e.g. cfSites) as well as process-based investigation of cloud maintenance and feedback mechanisms (e.g. cfSites, temperature and humidity tendency terms);

- developing and improving support infrastructure, including COSP, CFMIP-OBS and the CFMIP Diagnostic Codes Catalogue; and

- fostering collaboration with the observational and cloud process modelling communities via annual CFMIP meetings and internationally funded projects.

CFMIP is now entering its third phase, CFMIP-3, which will run in parallel with the current phase of the Coupled Model Intercomparison Project (CMIP6, Eyring et al., 2016). This paper documents the CFMIP-3/CMIP6 experiments and diagnostic outputs which constitute the CFMIP- 3 contribution to CMIP6. It is anticipated that CFMIP-3 will be broader than what is described here, for instance including studies with process models and informal CFMIP-3 experiments which are organized independently of CMIP6. Please refer to the CFMIP website for announcements of these other initiatives and CFMIP annual meetings.

CFMIP-3 touches, to differing degrees, on each of the three questions around which CMIP6 is organized. With its focus on cloud feedback, CFMIP-3 is central to CMIP6's attempt to answer the question "How does the Earth system respond to forcing?", but as illustrated in the remainder of this document, CFMIP-3 also offers the opportunity to contribute to the other two guiding questions of CMIP6. Through its strong model evaluation component, it stands to help to answer the question "What are the origins and consequences of systematic model biases?". CFMIP-3 will also help answer the question "How can we assess future climate changes given climate variability, climate predictability, and uncertainties in scenarios?". For example, the amip-piForcing experiment proposed below will support studies relating cloud variability and feedbacks on observable timescales to longterm cloud feedbacks (Andrews, 2014; Gregory and Andrews, 2016).

The CFMIP-3/CMIP6 experiments are outlined below in Sect. 2. Section 3 describes the diagnostics outputs proposed by CFMIP for the CFMIP-3/CMIP6 experiments and other experiments within CMIP. We provide a summary of the CFMIP-3 contribution to CMIP6 in Sect. 4. 


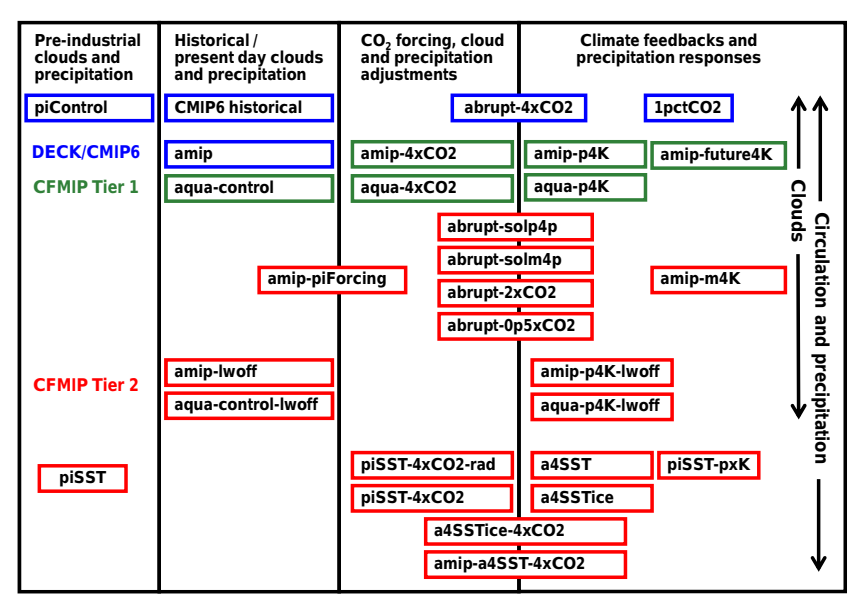

Figure 1. Summary of CFMIP-3/CMIP6 experiments and DECK + CMIP6 Historical experiments.

\section{CFMIP-3 experiments}

The CFMIP-3/CMIP6 experiments are summarized in Fig. 1 and Tables 1 and 2, and are described in detail below. Most of the CFMIP-3/CMIP6 experiments are based on $\mathrm{CO}_{2}$ concentration forced amip, piControl and abrupt-4xCO2 CMIP DECK (Diagnostic, Evaluation and Characterization of Klima) experiments (Eyring et al., 2016). Unless otherwise specified below, the CFMIP-3/CMIP6 experiments should be configured consistently with the DECK experiments on which they are based, using consistent model formulation, and forcings and boundary conditions as specified by Eyring et al. (2016). Following the CMIP6 design protocol, groups of experiments are motivated by science questions and are separated into Tiers 1 and 2 (Eyring et al., 2016). It is a requirement for participation by modelling groups in the CFMIP-3/CMIP6 model intercomparison that all Tier 1 experiments be performed and published through the ESGF, so as to support CFMIP's Tier 1 science question. Tier 2 experiments are optional, and are associated with additional science questions. Any subset of Tier 2 experiments may be performed. All model output archived by CFMIP3/CMIP6 is expected to be made available under the same terms as CMIP output. Most modelling groups currently release their CMIP data for unrestricted use. Our analysis plans for the CFMIP-3/CMIP6 experiments are summarized in Appendix A.

\subsection{CFMIP-3/CMIP6 Tier 1 experiments}

Lead coordinator: Mark Webb

Science question: what are the physical mechanisms underlying the range of cloud feedbacks and cloud adjustments predicted by climate models, and which of the cloud responses are the most credible?

Equilibrium climate sensitivity (ECS) can be estimated using an idealized AOGCM experiment such as the abrupt$4 x C O 2$ experiment in the CMIP6 DECK, at the same time statistically separating the global mean contributions from climate feedbacks and adjusted radiative forcing due to $\mathrm{CO}_{2}$ (Gregory et al., 2004; Andrews et al., 2012). However, understanding the physical processes underlying cloud feedbacks and adjustments requires diagnosis in SST forced experiments with atmosphere-only general circulation models (AGCMs), which can resolve cloud feedbacks and adjustments independently of each other and with minimal statistical noise at regional scales, while faithfully reproducing the inter-model differences in global values from the fully coupled models (Ringer et al., 2014). (The ability of these AGCM experiments to reproduce the inter-model differences in global cloud feedbacks and adjustments from coupled models indicates that they do not strongly depend on different ocean model formulations or SST biases.) The CFMIP2/CMIP5 amip $4 x \mathrm{CO} 2$ experiments, which quadrupled $\mathrm{CO}_{2}$ while leaving SSTs at present-day values (Bony et al., 2011), allowed the land-tropospheric adjustment process and the cloud adjustment to $\mathrm{CO}_{2}$ to be examined in this way for the first time in the multi-model context (Kamae and Watanabe, 2012; Ringer at al., 2014; Kamae et al., 2015) in conjunction with the CMIP5 sstClim/sstClim4xCO2 experiments which were based on climatological pre-industrial SSTs (Andrews et al., 2012; Zelinka et al., 2013; Vial et al., 2013). These experiments have additionally formed the basis for more indepth studies with individual models (e.g. Wyant et al., 2012; Kamae and Watanabe, 2013; Bretherton et al., 2014; Ogura et al., 2014). The CFMIP-2/CMIP5 amip4K and amipFuture SST perturbed atmosphere-only experiments (Bony et al., 2011) have been used to examine cloud feedbacks in greater detail (e.g. Brient and Bony, 2012; Bretherton et al., 2014; Lacagnina et al., 2014; Bellomo and Clement, 2015; Webb et al., 2015b), often in conjunction with simulator outputs (e.g. Gordon and Klein, 2014; Chepfer et al., 2014; Tsushima et al., 2016; Ceppi et al., 2016) and CFMIP process diagnostics (e.g. Webb and Lock, 2013; Sherwood et al., 2014; Brient et al., 2015; Webb et al., 2015a; Dal Gesso at al., 2015). Similarly, these experiments have been used to investigate regional responses of various quantities to direct radiative forcing due to increasing $\mathrm{CO}_{2}$ concentrations and/or increases in SST, including precipitation (e.g. Ma and Xie, 2013; Huang et al., 2013; Widlansky et al., 2013; Kent et al., 2015; Long et al., 2016), circulation (e.g. He et al., 2014; Zhou et al., 2014; Kamae et al., 2014; Bellomo and Clement, 2015; Shaw and Voigt, 2015) and stability (e.g. Qu et al., 2015).

A more idealized set of fixed SST experiments proposed by CFMIP-2 for CMIP5 (aquaControl, aqua $4 x \mathrm{CO}$, and aqua $4 K$ ) based on zonally symmetric, fixed season "aquaplanet" configurations without land have been shown to reproduce the inter-model differences in global mean cloud ad- 
Table 1. Summary of CFMIP-3/CMIP6 Tier 1 experiments.

\begin{tabular}{|c|c|c|c|c|}
\hline Experiment name & Experiment description/design & Configuration & Start year & Length \\
\hline amip & $\begin{array}{l}\text { This is a single ensemble member of the AMIP DECK experiment which con- } \\
\text { tains additional outputs which are required for model evaluation using COSP, } \\
\text { and as control values for model outputs in the amip-p } 4 \mathrm{~K} \text {, amip- } 4 \mathrm{xCO} \text {, amip- } \\
\text { future } 4 \mathrm{~K} \text { and amip-m } 4 \mathrm{~K} \text { experiments. }\end{array}$ & Atmos-only & 1979 & 36 \\
\hline amip-p4K & $\begin{array}{l}\text { As for the CFMIP-2/CMIP5 amip } 4 \mathrm{~K} \text { experiment. AMIP experiment where } \\
\text { SSTs are subject to a uniform warming of } 4 \mathrm{~K} \text {. }\end{array}$ & Atmos-only & 1979 & 36 \\
\hline amip-4xCO2 & $\begin{array}{l}\text { As for the CFMIP- } 2 / C M I P 5 \text { amip } 4 \times C O 2 \text { experiment. AMIP experiment where } \\
\text { SSTs are held at control values and the } \mathrm{CO}_{2} \text { seen by the radiation scheme is } \\
\text { quadrupled. }\end{array}$ & Atmos-only & 1979 & 36 \\
\hline amip-future $4 \mathrm{~K}$ & $\begin{array}{l}\text { As for the CFMIP-2/CMIP5 amipFuture experiment. AMIP experiment where } \\
\text { SSTs are subject to a composite SST warming pattern derived from coupled } \\
\text { models, scaled to an ice-free ocean mean of } 4 \mathrm{~K} \text {. }\end{array}$ & Atmos-only & 1979 & 36 \\
\hline aqua-control & $\begin{array}{l}\text { Extended version of the CFMIP-2/CMIP5 aquaControl experiment. Aquaplanet } \\
\text { (no land) experiment with no seasonal cycle forced with specified zonally sym- } \\
\text { metric SSTs. }\end{array}$ & Atmos-only & 1979 & 10 \\
\hline aqua-p4K & $\begin{array}{l}\text { Extended version of the CFMIP-2/CMIP5 aqua } 4 \mathrm{~K} \text { experiment. Aquaplanet ex- } \\
\text { periment where SSTs are subject to a uniform warming of } 4 \mathrm{~K} \text {. }\end{array}$ & Atmos-only & 1979 & 10 \\
\hline aqua-4xCO2 & $\begin{array}{l}\text { Extended version of the CFMIP-2/CMIP } 5 \text { aqua } 4 x \mathrm{CO} 2 \text { experiment. Aquaplanet } \\
\text { experiment where SSTs are held at control values and the } \mathrm{CO}_{2} \text { seen by the } \\
\text { radiation scheme is quadrupled. }\end{array}$ & Atmos-only & 1979 & 10 \\
\hline
\end{tabular}

justments and feedbacks from realistic experiments surprisingly effectively (Medeiros et al., 2008, 2015; Ringer et al., 2014), as well as many aspects of the zonal mean circulation response (Medeiros et al., 2015). This indicates that those features of the climate system excluded from these experiments (i.e. the ocean, land, seasonal cycle, monsoon and Walker circulations) are not central to understanding intermodel differences in global mean cloud feedbacks and adjustments, and demonstrates the value of aquaplanet experiments for investigating the origin of such differences, as well as differences in zonally averaged precipitation and circulation and their responses to climate change (e.g. Stevens et al., 2012; Bony et al., 2013; Oueslati and Bellon, 2013; Fermepin and Bony, 2014; Voigt and Shaw, 2015). The aquaplanet experiments have the benefit not only of being less computationally expensive than alternative experiments (requiring only $5-10$ years to get a robust signal); they are also much more straightforward to analyse, as their behaviour can mostly be characterized by examining zonal means, avoiding the analysis overhead of compositing which is generally required in realistic model configurations to isolate the various cloud regimes. Aquaplanet simulations (and other idealized experiments) are particularly effective at highlighting model differences, for instance in the placement of the tropical rain bands, or in the representation of cloud changes with warming, as it is not possible to tune them to observations in the same way as for more realistic configurations (e.g. Stevens and Bony, 2013).

The CFMIP-2/CMIP5 experiments and diagnostic outputs have thus enabled considerable progress on a number of questions. However, participation by a larger fraction of modelling groups is desired in CFMIP-3/CMIP6 to en- able a more comprehensive assessment of the uncertainties across the full multi-model ensemble. Our proposal is therefore to retain the CFMIP-2/CMIP5 experiments (known in CMIP5 as amip4K, amip $4 x C O 2$, amipFuture, aquaControl, aqua $4 x \mathrm{CO} 2$ and aqua4K) in Tier 1 for CFMIP-3/CMIP6. These are summarized in Table 1 (the names have been changed slightly compared to the CMIP5 equivalents to fit in with the wider naming convention of CMIP6). The set-up for each of these experiments is described below. (For output requirements from these and other experiments, please refer to Sect. 3.)

- amip: this is a single ensemble member of the CMIP DECK amip experiment which contains additional outputs which are required both for model evaluation using COSP and for interpretation of feedbacks and adjustments in conjunction with the amip-p4K, amip-4xCO2, amip-future $4 K$ and amip- $m 4 K$ experiments.

- amip-p4K (formerly amip4K): the same as the AMIP DECK experiment, except that SSTs are subject to a uniform warming of $4 \mathrm{~K}$. This warming should be applied to the ice-free ocean surface only. Sea ice and SSTs in grid boxes containing sea ice remain the same as in the AMIP DECK experiment.

- amip-future $4 K$ (formerly amipFuture): the same as the AMIP DECK experiment, except that a composite SST warming pattern derived from the CMIP3 coupled models is added to the amip SSTs (see Appendix C for details). As with the amip-p $4 K$ experiment, the warming pattern should only be applied to the ice-free ocean surface, and sea ice and SSTs in grid boxes containing sea 
Table 2. Summary of CFMIP-3/CMIP6 Tier 2 experiments.

\begin{tabular}{|c|c|c|c|c|}
\hline Experiment name & Experiment description/design & Configuration & Start year & Length \\
\hline amip-m4K & As for the amip experiment, but SSTs are subject to a uniform cooling of $4 \mathrm{~K}$. & Atmos-only & 1979 & 36 \\
\hline amip-lwoff & $\begin{array}{l}\text { As for the amip experiment, but with cloud-radiative effects switched off in the } \\
\text { LW radiation code. }\end{array}$ & Atmos-only & 1979 & 36 \\
\hline amip-p4K-lwoff & $\begin{array}{l}\text { As for the amip-p } 4 \mathrm{~K} \text { experiment, but with cloud-radiative effects switched off } \\
\text { in the LW radiation code. }\end{array}$ & Atmos-only & 1979 & 36 \\
\hline aqua-control-lwoff & $\begin{array}{l}\text { As for the aqua-control experiment, but with cloud-radiative effects switched } \\
\text { off in the LW radiation code. }\end{array}$ & Atmos-only & 1979 & 10 \\
\hline aqua-p4K-lwoff & $\begin{array}{l}\text { As for with the aqua-p } 4 \mathrm{~K} \text { experiment, but with cloud-radiative effects switched } \\
\text { off in the LW radiation code. }\end{array}$ & Atmos-only & 1979 & 10 \\
\hline abrupt-solp4p & $\begin{array}{l}\text { Conceptually similar to the abrupt- } 4 \mathrm{xCO} 2 \text { DECK experiment, except that the } \\
\text { solar constant rather than } \mathrm{CO}_{2} \text { is abruptly increased by } 4 \% \text {. }\end{array}$ & Coupled AOGCM & 1850 & 150 \\
\hline abrupt-solm $4 p$ & $\begin{array}{l}\text { Same as abrupt-solp } 4 p \text {, except that the solar constant is reduced by } 4 \% \text { rather } \\
\text { than increased. }\end{array}$ & Coupled AOGCM & 1850 & 150 \\
\hline abrupt-2xCO2 & Identical to the $\mathrm{DECK}$ abrupt $4 \mathrm{xCO} 2$, but at $2 \times \mathrm{CO}_{2}$ & Coupled AOGCM & 1850 & 150 \\
\hline abrupt-0p5xCO2 & Identical to the DECK abrupt $4 \times \mathrm{CO} 2$, but at $0.5 \times \mathrm{CO}_{2}$ & Coupled AOGCM & 1850 & 150 \\
\hline amip-piForcing & $\begin{array}{l}\text { Identical to the amip DECK experiment, but from } 1870 \text { to the present with } \\
\text { constant pre-industrial forcing levels (anthro \& natural). }\end{array}$ & Atmos-only & 1870 & 145 \\
\hline piSST & $\begin{array}{l}\text { An AGCM experiment with monthly varying SSTs, sea ice, atmospheric con- } \\
\text { stituents and any other necessary boundary conditions (e.g. vegetation if re- } \\
\text { quired) taken from each model's own piControl run (using the } 30 \text { years of pi- } \\
\text { Control that are parallel to years } 111-140 \text { of its abrupt } 4 \text { XCO2 run). Dynamic } \\
\text { vegetation should be turned off in the whole piSST set of experiments. }\end{array}$ & Atmos-only & Year 111 of abrupt- $4 \mathrm{xCO} 2$ & 30 \\
\hline piSST-pxK & $\begin{array}{l}\text { Same as piSST, but with a spatially and temporally uniform SST anomaly ap- } \\
\text { plied on top of the monthly varying piSST SSTs. The magnitude of the uniform } \\
\text { increase is taken from each model's global, climatological annual mean open } \\
\text { SST change between abrupt } 4 \mathrm{xCO} 2 \text { minus piControl (using the mean of years } \\
111-140 \text { of abrupt } 4 \times \mathrm{XO} 2 \text { and the parallel } 30 \text {-year section of piControl). }\end{array}$ & Atmos-only & Year 111 of abrupt- $4 \mathrm{xCO} 2$ & 30 \\
\hline piSST-4xCO2-rad & Same as piSST, but $\mathrm{CO}_{2}$ as seen by the radiation scheme is quadrupled. & Atmos-only & Year 111 of abrupt- $4 \mathrm{xCO} 2$ & 30 \\
\hline piSST-4xCO2 & $\begin{array}{l}\text { Same as piSST, but } \mathrm{CO}_{2} \text { is quadrupled. The increase in } \mathrm{CO}_{2} \text { is seen by both the } \\
\text { radiation scheme and vegetation. }\end{array}$ & Atmos-only & Year 111 of abrupt- $4 \mathrm{xCO} 2$ & 30 \\
\hline a4SST & $\begin{array}{l}\text { As for piSST, but with monthly varying SSTs taken from years } 111 \text { to } 140 \text { of } \\
\text { each model's own abrupt } 4 \mathrm{xCO} 2 \text { experiment instead of from piControl. Sea ice } \\
\text { is unchanged from piSST. }\end{array}$ & Atmos-only & Year 111 of abrupt-4xCO2 & 30 \\
\hline a4SSTice & $\begin{array}{l}\text { As for piSST, but with monthly varying SSTs and sea ice taken from years } 111 \\
\text { to } 140 \text { of each model's own abrupt } 4 \times \mathrm{xCO} 2 \text { experiment instead of from piControl. }\end{array}$ & Atmos-only & Year 111 of abrupt-4xCO2 & 30 \\
\hline a4SSTice-4xCO2 & $\begin{array}{l}\text { As for a4SSTice, but } \mathrm{CO}_{2} \text { is quadrupled, and the increase in } \mathrm{CO}_{2} \text { is seen by } \\
\text { both the radiation scheme and vegetation. }\end{array}$ & Atmos-only & Year 111 of abrupt- $4 \mathrm{xCO} 2$ & 30 \\
\hline amip-a4SST-4xCO2 & $\begin{array}{l}\text { Same as amip, but a patterned SST anomaly is applied on top of the monthly } \\
\text { varying amip SSTs. This anomaly is a monthly climatology, taken from each } \\
\text { model's own abrupt } 4 \mathrm{xCO} 2 \text { run minus piControl (using the mean of years } 111- \\
140 \text { of abrupt } 4 \mathrm{xCO} 2 \text { and the parallel } 30 \text {-year section of piControl). } \mathrm{CO}_{2} \text { is } \\
\text { quadrupled, and the increase in } \mathrm{CO}_{2} \text { is seen by both the radiation scheme and } \\
\text { vegetation. }\end{array}$ & Atmos-only & 1979 & 36 \\
\hline
\end{tabular}

ice should remain the same as in the AMIP DECK experiment. The warming pattern should be scaled to ensure that the global mean SST increase averaged over the ice-free oceans is $4 \mathrm{~K}$. Care should be taken to ensure that SSTs are increased in any inland bodies of water and near coastal edges, for example by linearly interpolating the provided warming pattern dataset to fill in missing data before re-gridding to the target resolution.

- amip-4xCO2 (formerly amip4xCO2): the same as the amip experiment within DECK, except that the $\mathrm{CO}_{2}$ concentration seen by the radiation scheme is quadrupled. The $\mathrm{CO}_{2}$ seen by the vegetation should be the same as in the AMIP DECK experiment. This experiment gives an indication of the adjusted radiative forcing due to $\mathrm{CO}_{2}$ quadrupling, including strato- spheric, land surface, tropospheric and cloud adjustments. (Given the names of other CMIP6 experiments, this experiment might have been better named amip$4 x \mathrm{CO} 2-\mathrm{rad}$, but this inconsistency was only noticed after the experiment names were finalized and propagated to the ESGF.)

The configurations of the aqua-control, aqua-p $4 K$ and aqua$4 x \mathrm{CO} 2$ experiments are unchanged compared to their equivalents in CFMIP-2/CMIP5, except that the simulation length has been extended to 10 years to improve the signal-to-noise ratio. Further details of their experimental set-up are included in Appendix B.

We also propose using the Tier 1 experiments as the foundation for further experiments planned in the context of the Grand Challenge on Clouds, Circulation and Climate Sen- 
sitivity (Bony et al., 2015). These will include for example sensitivity experiments to assess the impacts of different physical processes on cloud feedbacks and regional circulation/precipitation responses and also to test specifically proposed cloud feedback mechanisms (e.g. Webb et al., 2015b; Ceppi et al., 2015). Additional experiments further idealizing the aquaplanet framework to a non-rotating rotationally symmetric case are also under development (e.g. Popke et al., 2013). These will be proposed as additional Tier 2 experiments at a future time or coordinated informally outside of CMIP6.

\section{2 amip minus $4 \mathrm{~K}$ experiment (Tier 2)}

\section{Lead coordinators: Mark Webb and Bjorn Stevens}

Science question: are cloud feedbacks consistent for climate cooling and warming, and, if not, why?

There is some evidence to suggest that cloud feedbacks might operate differently in response to cooling rather than warming. For example, Yoshimori et al. (2009) found a positive shortwave cloud feedback in a $\mathrm{CO}_{2}$ doubling experiment with a particular GCM, but noted a tendency for it to become weaker or even negative in cooling experiments designed to replicate the climate of the Last Glacial Maximum. They suggested that this might be related to different displacements of mixed-phase clouds in the two scenarios. For small enough changes where linearity is a good approximation, one would expect the cloud response to cooling and warming to be the same, differing only in sign, resulting in an identical cloud feedback expressed per degree of global temperature change, but for larger perturbations this symmetry of response may no longer hold. A warming or cooling of the atmosphere of equal magnitude while maintaining relative humidity will for example generate different changes in absolute humidity and its horizontal and vertical gradients, which have been linked to cloud feedbacks (Brient and Bony, 2013; Sherwood et al., 2014), the atmospheric lapse rate and circulation which influences clouds and depends in part on the absolute humidity (Held and Soden, 2006; Qu et al., 2015) and additionally on extratropical cloud optical depth feedbacks which may be related to adiabatic cloud liquid water contents (Gordon and Klein, 2014) or phase changes that depend upon whether a given volume crosses the $0^{\circ}$ isotherm in the climate change (Ceppi et al., 2015).

The configuration of the amip- $m 4 K$ experiment will be the same as the amip- $p 4 K$ experiment, except that the sea surface temperatures are uniformly reduced by $4 \mathrm{~K}$ rather than increased. This cooling should be applied to sea-ice-free grid boxes only. Sea ice and SSTs in grid boxes containing sea ice should remain the same as in the AMIP DECK experiment. In models which employ a fixed lower threshold near freezing for the SST used in the calculation of the surface fluxes, this should ideally also be reduced by $4 \mathrm{~K}$. This ex- periment will contain CFMIP COSP and process outputs so as to support the investigation of inconsistent responses of clouds to a cooling vs. a warming climate in a controlled way through comparison with the amip-p $4 K$ experiment. This experiment also complements the abrupt $0.5 \times \mathrm{CO}_{2}$ and the $-4 \%$ solar experiments in that one can identify asymmetries in the warming/cooling response with and without interactions with the ocean. As such we hope that these experiments will provide useful synergies with the Palaeoclimate Model Intercomparision Project (PMIP) CMIP6 experiments (Kageyama et al., 2016), for example in interpreting differing cloud feedbacks between future $\mathrm{CO}_{2}$ forced experiments and those representing the Last Glacial Maximum, as highlighted by Yoshimori et al. (2009).

\subsection{Atmosphere-only experiments without longwave cloud-radiative effects (Tier 2)}

Lead coordinators: Sandrine Bony and Bjorn Stevens

Science question: how do cloud-radiative effects impact the structure, the strength and the variability of the general atmospheric circulation in present and future climates?

It is increasingly recognized that clouds, and atmospheric cloud-radiative effects in particular, play a critical role in the general circulation of the atmosphere and its response to global warming or other perturbations: they have been found to modulate the structure, the position and shifts of the ITCZ (e.g. Slingo and Slingo, 1988; Randall et al., 1989; Sherwood et al., 1994; Bergman and Hendon, 2000; Hwang and Frierson, 2013; Fermepin and Bony 2014; Voigt et al., 2014; Loeb et al., 2015), the organization of convection in tropical waves, Madden-Julian oscillations and other forms of convective aggregation (e.g. Lee et al., 2001; Lin et al., 2004; Bony and Emanuel, 2005; Zurovac-Jevtic et al., 2006; Crueger and Stevens, 2015; Muller and Bony, 2015), the extra-tropical circulation and the position of eddy-driven jets (e.g. Ceppi et al., 2012, 2014; Grise and Polvani, 2014; Li et al., 2015; Voigt and Shaw, 2015), and modes of inter-annual to decadal climate variability (e.g. Bellomo et al., 2015; Rädel et al., 2016; Yuan et al., 2016). A better assessment of this role would greatly help to interpret model biases (how much do biases in cloud-radiative properties contribute to biases in the structure of the ITCZ, in the position and strength of the storm tracks, in the lack of intra-seasonal variability, etc.) and to inter-model differences in simulations of the current climate and in climate change projections (especially changes in regional precipitation and extreme events). More generally, a better understanding of how clouds couple to the circulation is expected to improve our ability to answer the four science questions raised by the WCRP Grand Challenge on Clouds, Circulation and Climate Sensitivity (Bony et al., 2015).

These questions provided the scientific motivation for the Clouds On/Off Klima Intercomparison Experiment 
(COOKIE) project proposed by European consortium EUCLIPSE and CFMIP (Stevens et al., 2012). The COOKIE experiments, which have been run by four to eight climate models (depending on the experiment), switched off the cloudradiative effects (clouds seen by the radiation code - and the radiation code only - were artificially made transparent) in an atmospheric model forced by prescribed SSTs. By doing so, the atmospheric circulation could feel the lack of cloud-radiative heating within the atmosphere, but the land surface could also feel the lack of cloud shading, which led to changes in land surface temperatures and land-sea contrasts. The change in circulation between On and Off experiments resulted from both effects, obscuring to some degree the mechanisms through which the atmospheric cloudradiative effects interact with the circulation for given surface boundary conditions. As the longwave cloud-radiative effects are felt mostly within the troposphere (representing most of the net atmospheric cloud-radiative heating), while the shortwave effects are felt mostly at the surface (e.g. L'Ecuyer and McGarragh, 2010; Haynes et al., 2013), we could better isolate the role of tropospheric cloud-radiative effects on the circulation by running atmosphere-only experiments in which clouds are made transparent to radiation only in the longwave. In this configuration, the models will have a shortwave cloud feedback but no longwave cloud feedback. We note that the presence of clouds does affect the shortwave radiative heating of the atmosphere, although this is a much smaller effect than its longwave equivalent (e.g. Pendergrass and Hartmann, 2014).

Therefore we propose in Tier 2 a set of simple experiments similar to the amip, amip-p4K, aqua-control and aqua-p4K experiments within Tier 1, but in which cloud-radiative effects are switched off in the longwave part of the radiation code while retaining those in the shortwave part (Fermepin and Bony, 2014). Care should also be taken to remove the effects of cloud on any longwave cooling used in other model schemes (e.g. turbulent mixing) if these are calculated independently of the radiation scheme. These experiments will be referred to as amip-lwoff, amip-p4K-lwoff, aqua-controllwoff and aqua-p $4 K$-lwoff. The analysis of idealized (aquaplanet) experiments will allow us to assess the robustness of the impacts found in more realistic (AMIP) configurations. It will also facilitate the interpretation of the results using simple dynamical models or theories, in collaboration with large-scale dynamicists (e.g. DynVar). The comparison of the inter-model spread of simulations between the standard and "lwoff" experiments for present-day and warmer climates will help to identify which aspects of the inter-model spread depend on the representation of cloud-radiative effects, and which aspects do not, thus better highlighting other sources of spread. An alternative method (proposed by Aiko Voigt) was also considered, in which clear-sky heating rates would be applied in the atmosphere while retaining the allsky fluxes at the surface. Although this approach would potentially isolate the effects of cloud heating in the atmosphere more cleanly than the lwoff experiments proposed here, it is yet to be demonstrated in a pilot study, and is considered more technically difficult to implement than the lwoff experiments, which are very similar to those piloted by Fermepin and Bony (2014).

\subsection{Abrupt $\pm 4 \%$ solar forced AOGCM experiments (Tier 2)}

Lead coordinators: Chris Bretherton, Roger Marchand, and Bjorn Stevens

Science question: how do responses in the climate system due to changes in solar forcing differ from changes due to $\mathrm{CO}_{2}$, and is the response sensitive to the sign of the solar forcing?

While rapid adjustments in clouds and precipitation can easily be separated from conventional feedbacks in SST forced experiments, such a separation in coupled models is complicated by various issues, including the response of the ocean on decadal timescales. A number of studies have examined cloud feedbacks in coupled models subject to a solar forcing, which is generally associated with much smaller global cloud and precipitation adjustment, due to a smaller atmospheric absorption for a given top of atmosphere forcing (e.g. Lambert and Faull, 2007; Andrews et al., 2010), but the regional cloud and precipitation changes have yet to be rigorously investigated across models. Solar forcing also differs from greenhouse forcing through its different fingerprint on the vertical structure of warming (Santer et al., 2013) and small changes in the radiative heating near the tropopause may project measurably on tropospheric climate (e.g. Butler et al., 2010), for instance by influencing the baroclinicity in the upper troposphere and thus the storm tracks (Bony et al., 2015).

A $+4 \%$ solar experiment abrupt-solp $4 p$ is proposed which is analogous to the abrupt-4xCO2 experiment, but rather than changing $\mathrm{CO}_{2}$ it would abruptly increase the solar constant by $4 \%$ and keep it fixed for 150 years, resulting in a global mean radiative forcing of a similar magnitude to that due to $\mathrm{CO}_{2}$ quadrupling. When changing the solar constant, the shape of the spectral solar irradiance distribution should remain consistent with that in the piControl experiment. This experiment complements the DECK abrupt$4 x \mathrm{CO} 2$ experiment, tests the forcing feedback framework for analysing climate change, and would support our understanding of regional responses of the coupled system with and without $\mathrm{CO}_{2}$ adjustments. The complementary $-4 \%$ abrupt solar forcing experiment (abrupt-solm $4 p$ ) would allow the examination of feedback asymmetry under climate cooling, and would also help with the interpretation of model responses to geo-engineering scenarios and volcanic forcing, and of past climate signals. 


\section{5 nonLinMIP abrupt $2 \times \mathrm{CO}_{2}$ and abrupt $0.5 \times \mathrm{CO}_{2}$ experiments (Tier 2)}

\section{Lead coordinator: Peter Good}

Science question: to what extent is regional-scale climate change per $\mathrm{CO}_{2}$ doubling state-dependent (non-linear); what are the associated mechanisms; and how does this affect our understanding of climate model uncertainty?

Recent studies with individual, or a small number of climate models, have found substantial non-linearities in regional-scale precipitation change (Good et al., 2012; Chadwick and Good, 2013) associated with robust physical mechanisms (Chadwick and Good, 2013). Significant nonlinearity has also been found in global- and regional-scale warming (e.g. Colman and McAvaney, 2009; Jonko et al., 2013; Good et al., 2015; Meraner et al., 2013) and ocean heat uptake (Bouttes et al., 2015).

To address this science question, we propose two new experiments for Tier 2, abrupt $2 x \mathrm{CO} 2$ and abrupt0p5xCO2. These are the same as the DECK abrupt $4 x \mathrm{CO} 2$ experiment except that $\mathrm{CO}_{2}$ concentrations are doubled and halved, respectively, relative to the pre-industrial control. These experiments are based on a proven analysis approach, including traceability of these experiments to transient-forcing simulations (Good et al., 2016), to explore global- and regionalscale non-linear responses, highlighting different behaviour under business-as-usual scenarios, mitigation scenarios and palaeoclimate simulations. Additionally, comparisons of the abrupt-2xCO2 and abrupt-4xCO2 experiments will help to establish the extent to which the latter accurately estimates the equilibrium climate sensitivity to $\mathrm{CO}_{2}$ doubling (e.g. Gregory et al., 2004; Block and Mauritsen, 2013). Additional experiments (Good et al., 2016) may be proposed for Tier 2 in the future, or coordinated informally by CFMIP-3 outside of CMIP6. These include 100-year extensions to abrupt$4 x \mathrm{CO} 2$ and abrupt-2xCO2, a $1 \%$ ramp-down from the end of the 1 pctCO2 experiment, and an abrupt step-down to $1 \times \mathrm{CO}_{2}$ from year 100 of the abrupt-4xCO2. These would be used to explore longer-timescale responses, quantify non-linear mechanisms more precisely and understand the reversibility of climate change.

\subsection{Feedbacks in amip experiments (Tier 2)}

Lead coordinator: Timothy Andrews

Science question: are climate feedbacks during the 20th century different to those acting on long-term climate change?

Recent studies have shown significant time variation in climate feedbacks in response to $\mathrm{CO}_{2}$ quadrupling (e.g. Andrews et al., 2012, 2015; Geoffroy et al., 2013; Armour et al., 2013). This raises the possibility that feedbacks during the 20th century may be different to those acting on longterm change and hence have the potential to alleviate the apparent discrepancy between estimates of climate sensitivity from comprehensive climate models and from simple climate models fitted to observed warming trends (Collins et al., 2013). For example, Gregory and Andrews (2016) found that two models forced with observed monthly 20th century SST and sea-ice variations simulated effective climate sensitivities of about $2 \mathrm{~K}$, whereas these same models forced with patterns of long-term SST change simulated effective climate sensitivities of over 3 and $4 \mathrm{~K}$.

The previous CFMIP-2/CMIP5 design was unable to diagnose the time variation of feedbacks of explicit relevance to the historical period, because this requires the removal of the time-varying forcing. To address this we propose an additional experiment called amip-piForcing (amip pre-industrial forcing) following the design of Andrews (2014) and Gregory and Andrews (2016). This experiment is the same as the AMIP DECK experiment (i.e. using observed monthly updating SSTs and sea ice), but run for the period 1870 present and with constant pre-industrial forcings (i.e. all anthropogenic and natural forcing boundary conditions identical to the piControl experiment). Since the forcing constituents do not change in this experiment, it readily allows a simple diagnosis of the simulated atmospheric feedbacks to observed SST and sea-ice changes, which can then be compared to feedbacks representative of long-term change and climate sensitivity (e.g. from abrupt-4xCO2 or amip-p $4 \mathrm{~K}$ ). The experiment has the additional benefit, by differencing with the standard amip run that includes time-varying forcing agents, of providing detailed information on the transient effective radiative forcing and adjustments in models during the amip period (Andrews, 2014). This can then be compared to the forcings diagnosed in the Radiative Forcing Model Intercomparison Project (RFMIP, Pincus et al., 2016, who use a pre-industrial climate baseline) to test for any dependence of forcing and adjustments on the climate state. Time-varying feedbacks in the amip experiment could alternatively be diagnosed by subtracting a time-varying radiative forcing diagnosed from RFMIP experiments. However, the amip-piForcing approach has the benefit of diagnosing the time-varying feedbacks over the full 1870-present period rather than the last 36 years, and does so with reference to a single experiment, which reduces noise compared to that which would be present with a double difference of the amip experiment and two RFMIP experiments. Also, the inclusion of CFMIP process diagnostics in the amip-piForcing experiment will enable a deeper understanding of the factors underlying forcing and feedback differences in the present and future climate.

We also consider the time variation of feedbacks in abrupt$4 x \mathrm{CO} 2$ experiments to be an important area to be investigated, as this can have a substantial impact on estimates of equilibrium sensitivity (e.g. Geoffroy et al., 2013). Andrews 
et al. (2015) investigated such effects using two atmosphereonly GCMs forced with SSTs and sea ice from their own abrupt- $4 x \mathrm{CO} 2$ experiments, and attributed the time variation in the feedbacks to changes in the pattern of surface warming. Pilot studies are ongoing to develop similar experiments based on a composite SST pattern response more representative of the CMIP5 ensemble mean. We plan to organize an informal pilot intercomparison based on this within CFMIP3 and may subsequently propose these experiments as an extension to the CFMIP-3/CMIP6 experiment set.

\subsection{Time slice experiments for understanding regional climate responses to $\mathrm{CO}_{2}$ (Tier 2)}

Lead coordinators: Robin Chadwick, Hervé Douville and Christopher Skinner

Science questions:

- How do regional climate responses (e.g. of precipitation) in a coupled model arise from the combination of responses to different aspects of $\mathrm{CO}_{2}$ forcing and sea surface warming (uniform SST warming, patterned SST warming, sea-ice change, direct $\mathrm{CO}_{2}$ effect, plant physiological effect)?

- Which aspects of forcing/warming are most important for causing inter-model uncertainty in regional climate projections?

- Can inter-model differences in regional projections be related to underlying structural or resolution differences between models through improved process understanding, and could this help us to constrain the range of regional projections?

- What impact do coupled model SST biases have on regional climate projections?

The CFMIP-2/CMIP5 set of idealized amip experiments (e.g. amip $4 K$, amipFuture) have allowed the contribution of different aspects of SST warming and increased $\mathrm{CO}_{2}$ concentrations to the projections of fully coupled GCMs to be examined (e.g. Bony et al., 2013; Chadwick et al., 2014; $\mathrm{He}$ and Soden, 2015). However, the amip experiments were not designed to replicate coupled GCM responses on a regional scale, and large discrepancies exist between the two in many regions, particularly when individual models are examined instead of the ensemble mean (Chadwick, 2016). This is largely due to the choice of present-day and future SST boundary conditions used in the amip experiments, as well as missing processes such as the plant physiological response to $\mathrm{CO}_{2}$, rather than the lack of air-sea coupling (Skinner et al., 2012).

We propose a new set of seven 30-year atmosphere-only time slice experiments, and one 36-year amip-style experiment, to decompose the regional responses of each model's
abrupt-4xCO2 run into separate responses to each aspect of forcing and warming (uniform SST warming, pattern SST change, sea-ice change, increased $\mathrm{CO}_{2}$, plant physiological effect). These are forced with monthly and annually varying monthly mean SSTs and sea ice, which reproduce regional precipitation patterns more accurately than is possible using climatological SST forcing (Skinner et al., 2012). As well as allowing regional responses in each individual model to be better understood, this set of experiments should prove especially useful for understanding the causes of model uncertainty in regional climate change.

The experiments are

1. piSST - an AGCM experiment with monthly and annually varying SSTs, sea ice, atmospheric constituents and any other necessary boundary conditions (e.g. vegetation if required) taken from a section of each model's own piControl run, using the 30 years of piControl that are parallel to years 111-140 of its abrupt-4xCO2 run. Note that dynamic vegetation (if included in the model) should not be turned on in any of the piSST set of experiments;

2. piSST-pxK - same as piSST, but with a global spatially and temporally uniform SST anomaly applied on top of the monthly - and annually - varying piSST SSTs. The magnitude of the uniform increase is taken from each model's global, climatological annual mean open SST change between abrupt-4xCO2 and piControl (using the mean of years 111-140 of abrupt-4xCO2 and the parallel 30-year section of piControl). Sea ice is unchanged from piSST values;

3. piSST-4xCO2-rad - same as piSST, but $\mathrm{CO}_{2}$ as seen by the radiation scheme is quadrupled;

4. piSST-4xCO2 - same as piSST but with $\mathrm{CO}_{2}$ quadrupled, and this increase is seen by both the radiation scheme and the plant physiological effect. If a model does not include the plant physiological response to $\mathrm{CO}_{2}$, then piSST-4xCO2 can be omitted from the set of piSST experiments for that model;

5. a4SST - same as piSST, but with monthly and annually varying SSTs taken from years 111 to 140 of each model's own abrupt-4xCO2 experiment instead of from piControl (sea ice is unchanged from piSST);

6. a4SSTice - same as piSST, but with monthly and annually varying SSTs and sea ice taken from years 111 to 140 of each model's own abrupt-4xCO2 experiment instead of from piControl;

7. a4SSTice-4xCO2 - same as piSST, but with monthly and annually varying SSTs and sea ice taken from years 111 to 140 of each model's own abrupt-4xCO2 experiment instead of from piControl. $\mathrm{CO}_{2}$ is also quadrupled, and 
is seen by both the radiation scheme and the plant physiological effect (if included in the model). a4SSTice$4 x \mathrm{CO} 2$ is used to establish whether a time slice experiment can adequately recreate the coupled abrupt$4 x \mathrm{CO} 2$ response in each model, and then forms the basis for a decomposition using the other experiments. The time slice experiments can be combined in various ways to isolate the climate response to each individual aspect of forcing and warming. For example, the response to SST pattern change is given by taking the difference between a4SST and piSST-pxK, and the plant physiological response is found by taking the difference between piSST-4xCO2 and piSST-4xCO2-rad.

8. We also propose an additional amip-based experiment, amip-a4SST-4xCO2: the same as amip, but a patterned SST anomaly is applied on top of the monthly and annually varying amip SSTs. This anomaly is a monthly climatology, taken from each model's own abrupt-4xCO2 run minus piControl (using the mean of years 111140 of abrupt-4xCO2 and the parallel 30-year section of piControl). $\mathrm{CO}_{2}$ is quadrupled, and the increase in $\mathrm{CO}_{2}$ is seen by both the radiation scheme and vegetation. Comparison of amip-a4SST-4xCO2 and a4SSTice$4 x \mathrm{CO} 2$ should help to illuminate the impact of SST biases on regional climate responses in each model, and how this contributes to inter-model uncertainty.

\section{CFMIP recommended diagnostic outputs for CMIP experiments}

The CFMIP-3/CMIP6 specific diagnostic request is designed to address the following questions.

1. How well do clouds and other relevant variables simulated by models agree with observations?

2. What physical processes and mechanisms are important for a credible simulation of clouds, cloud feedbacks and cloud adjustments in climate models?

3. Which models have the most credible representations of processes relevant to the simulation of clouds?

4. How do clouds and their changes interact with other elements of the climate system?

The set of diagnostic outputs recommended for CFMIP3/CMIP6 is based on that from CFMIP-2/CMIP5, with some modifications. The request outlined below is in three parts. The first part describes an updated set of CFMIP process diagnostics (based on those in CFMIP-2/CMIP5 which are documented at http://cmip-pcmdi.llnl.gov/cmip5/ output_req.html) in terms of the various groups of variables and the experiments in which they are requested. This set was drawn up by the CFMIP committee and ratified by the modelling groups following a presentation at the 2014 CFMIP meeting. The second part describes recommendations for COSP outputs in the CFMIP-3/CMIP6, CMIP DECK and CMIP6 Historical experiments. The third part describes additional diagnostics requested for evaluation of the mean diurnal cycle of tropical clouds and radiation. The summaries below give an overview of the diagnostic request; however, the definitive and detailed specification is documented in the CMIP6 data request, available at https://www.earthsystemcog.org/projects/wip/ CMIP6DataRequest. The changes in the CFMIP-3/CMIP6 diagnostics relative to those requested for CFMIP-2/CMIP5 are additionally motivated and detailed in the CFMIP CMIP6 proposal document which is available from the CFMIP website.

CMIP mandates that for participation in CFMIP-3/CMIP6, modelling groups must commit to performing all of the Tier 1 experiments. In recognition that sufficient resources are not available for all groups to prepare all of the CFMIP3/CMIP6-specific diagnostics, these diagnostics are considered to be Tier 2, i.e. not compulsory for participation in CFMIP-3/CMIP6. Nonetheless, these diagnostics are extremely valuable and all groups with the capacity to do so are very strongly encouraged to provide the additionally requested CFMIP-3/CMIP6-specific diagnostics.

In the case where CFMIP-3/CMIP6-specific outputs are requested in the DECK and CMIP6 Historical experiments, and modelling groups run more than one ensemble member of an experiment, we request that each set of CFMIP3/CMIP6-specific outputs be submitted for one ensemble member only. Having different CFMIP variables in different ensemble members is acceptable, but submitting them all in the same ensemble member is preferable. We request that the modelling groups provide information on which CFMIP diagnostic sets are submitted in which ensemble members so that this information can be made available to those who may be analysing the output. Our analysis plans for the CFMIP diagnostic outputs in the CMIP DECK, CMIP6 Historical and CFMIP-3/CMIP6 experiments, including details of the CFMIP Diagnostics Code Catalogue, are summarized in Appendix A.

\subsection{Process outputs}

In CFMIP-2/CMIP5, instantaneous high-frequency "cfSites" outputs were requested for 120 locations in the amip, amip4K, amipFuture and amip $4 x \mathrm{CO} 2$ experiments, and for 73 locations along the Greenwich Meridian in the aquaplanet experiments, to support understanding and evaluation of clouds and their interactions with convection and other processes. The 120 locations include the locations of instrumented sites (ARM and CloudNet stations, Dome C, etc.), the transect associated with the GCSS Pacific Cross-section Intercomparison (GPCI), past field campaigns (DYCOMSII, NARVAL, HOPE, VOCALS, ASTEX and AMMA transects, TOGA-COARE, RICO, etc.) and a number of cli- 


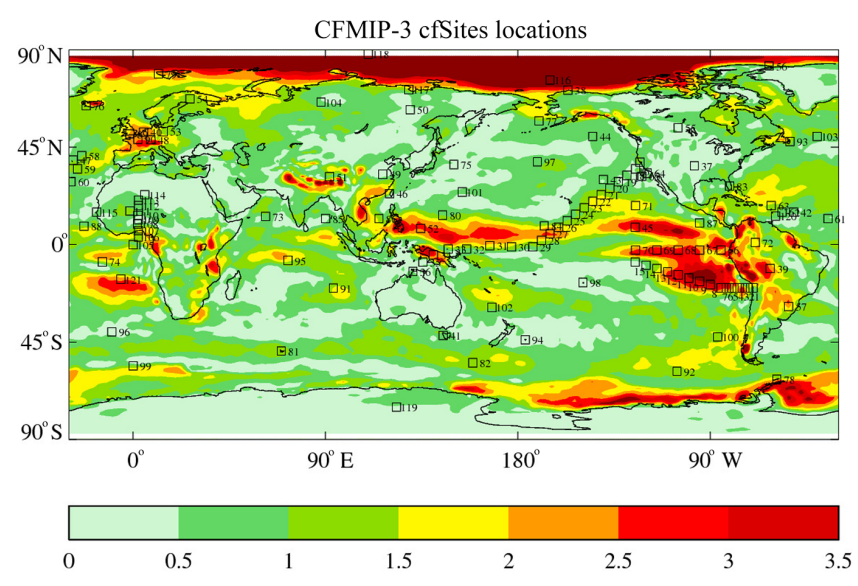

Figure 2. CFMIP-3/CMIP6 cfSites locations. The contours give an indication of inter-model spread in cloud feedback from the CFMIP-2/CMIP5 amip/amip4K experiments (please refer to Webb et al., 2015a, for details).

mate regimes that contribute substantially to the inter-model spread of cloud feedbacks in climate change (Webb et al., 2015a). These outputs have so far been used to evaluate the models with in situ measurements (e.g. Nuijens et al., 2015a, b; Neggers, 2015), to investigate the diurnal cycle of cloud feedbacks (Webb et al., 2015a) and to compare cloud feedbacks in climate models with SCM and LES outputs from CGILS (Dal Gesso at al., 2015). We have added St. Helena to the list of locations in light of upcoming field work, increasing the total number of locations to 121 for CFMIP3/CMIP6. A text file containing the list of locations is available in the Supplement and on the CFMIP website; these are also presented graphically in Fig. 2.

For CFMIP-3 cfSites outputs are now requested for one ensemble member of the AMIP DECK experiment, and the amip-p $4 \mathrm{~K}$ and amip- $4 x \mathrm{CO} 2$ experiments. Outputs should be provided for the full duration of each experiment. The sampling interval should be the integer multiple of the model time step that is nearest to $30 \mathrm{~min}$ and divides into $60 \mathrm{~min}$ with no remainder: e.g. $30 \mathrm{~min}$ for a 30,15 or $10 \mathrm{~min}$ time step or $20 \mathrm{~min}$ for a $20 \mathrm{~min}$ time step. Outputs should be instantaneous (i.e. not time means) and from the nearest grid box (i.e. no spatial interpolation). We have dispensed with the cfSites outputs in the aquaplanet and amip-future $4 K$ experiments because these have been less widely used compared to those from the other experiments.

The cfSites outputs from CFMIP-3/CMIP6 provide instantaneous outputs of a range of quantities (including temperature and humidity tendency terms) in experiments which can be used to evaluate the present-day relationships of clouds to cloud controlling factors using in situ measurements, and at the same time explore how these relationships affect cloud feedbacks and cloud adjustments. An increasing wealth of observational data with which to evaluate the models using these outputs is available or in the planning stage, for example from the Barbados Cloud Observatory (Stevens et al., 2015), the ARM Program (e.g. Wood et al., 2015; Marchand et al., 2015) or within the German national project on highdefinition clouds and precipitation for climate-prediction, $\mathrm{HD}(\mathrm{CP})^{2}$, inclusive of its observational prototype experiment (HOPE), and which has collected observations over Germany following conventions adopted for CMIP (Andrea Lammert, personal communication).

CFMIP-2 also requested cloud, temperature and humidity tendency terms from convection, radiation, dynamics, etc. in the amip, amip $4 \mathrm{~K}$, amipFuture and amip $4 x \mathrm{CO} 2$, aquaControl, aqua $4 x \mathrm{CO} 2$ and aqua $4 \mathrm{~K}$ experiments, as global monthly mean outputs and high-frequency outputs at fixed locations (Bony et al., 2011). Upward and downward radiative fluxes on model levels were also requested in these experiments, and for instantaneous $\mathrm{CO}_{2}$ quadrupling in the amip experiment only. Temperature and humidity tendency terms in particular have been shown to be useful for understanding the roles of different parts of the model physics in cloud feedbacks (e.g. Webb and Lock, 2013; Demoto et al., 2013; Sherwood et al., 2014; Brient et al., 2015) and cloud adjustments (e.g. Kamae and Watanabe, 2012; Ogura et al., 2014) as well as in understanding clouds and circulation in the present climate (e.g. Williams et al., 2013; Oueslati and Bellon, 2013; Xavier et al., 2015). They have also been used to understand regional warming patterns such as polar amplification in coupled models (e.g. Yoshimori et al., 2014).

In CFMIP-3/CMIP6 we have improved the definitions of the temperature and humidity tendency terms, and added some additional terms such as clear-sky radiative heating rates to more precisely quantify the contributions of different processes to the temperature and humidity budget changes underlying cloud feedbacks and adjustments. We have dispensed with the cloud water tendency terms because these have been less widely used than the temperature and humidity tendencies.

A shortcoming of the CMIP5 protocol was that we were unable to interpret the physical feedback mechanisms in coupled model experiments due to a lack of process diagnostics. For this reason in CMIP6 we are requesting these budget terms in the DECK abrupt- $4 x \mathrm{CO} 2$ experiment and the preindustrial control as well as one ensemble member of the AMIP DECK experiment, and all of the CFMIP-3/CMIP6 experiments listed in Sects. 2.1-2.6.

Clustering approaches (e.g. Jakob and Tselioudis, 2003) are now commonly used for assessing the contributions of different cloud regimes (e.g. stratocumulus, trade cumulus, frontal clouds) to present-day biases in cloud simulations and to inter-model differences in cloud feedbacks (e.g. Williams and Webb, 2009; Tsushima et al., 2013, 2016). We have also added some additional daily 2-D fields to the standard package of CFMIP daily outputs to allow further investigation of feedbacks between clouds and aerosols associated with the changing hydrological cycle (aerosol loadings and cloud top 
effective radii/number concentrations) and a clearer diagnosis of the roles of convective and stratiform clouds (convective vs. stratiform ice and condensed water paths and cloud top effective radii/number concentrations).

\subsection{COSP outputs}

This section motivates and summarizes the COSP outputs requested from the DECK, CMIP6 Historical and CFMIP3/CMIP6 experiments, as well as a corresponding set of observations.

There is no unique definition of clouds or cloud types, neither in models nor in observations. Therefore, to compare models with observations, and even to compare models with each other, it is necessary to use a consistent definition of clouds between the model and the satellite product in question (i.e. be "definition-aware"). Further complicating matters: climate model grid boxes (typically $1^{\circ}$ ) are much larger than the scales over which many satellite observations are made (typically $<10 \mathrm{~km}$ ). As a result, one must downscale the climate model cloud properties to the observation scale (i.e. be "scale-aware"). The CFMIP Observation Simulator Package (COSP) enables definition-aware and scale-aware comparisons between models and multiple sets of observations by producing cloud diagnostics from model simulations that are quantitatively comparable to a variety of satellite products from ISCCP, CloudSat, CALIPSO, MODIS, MISR and Parasol (Bodas-Salcedo et al., 2011). COSP enables a more quantitative comparison of model outputs with satellite cloud products, which often sub-sample low-level clouds in the presence of high-level clouds due to the effects of cloud overlap and attenuation (e.g. Yu et al., 1996). COSP also provides histograms of various cloud properties as a function of height or pressure which are directly comparable with satellite products and cannot be calculated correctly from time mean model outputs. The multiple simulators within COSP allow a multi-faceted evaluation of clouds in models whereby the strengths and weaknesses of different satellite products may be considered together.

COSP is increasingly being used not only for model intercomparison activities, but also as part of the model development and evaluation process by modelling groups (e.g. Marchand et al., 2009; Zhang et al., 2010; Kay et al., 2012; Franklin et al., 2013; Lacagnina and Selten, 2014; Nam et al., 2014; Williams et al., 2015; Konsta et al., 2015). Many of the standard monthly and daily COSP outputs have been shown to be valuable in the CMIP5 experiments, not only for cloud evaluation, allowing a detailed evaluation of clouds and precipitation, and their interaction with radiation (e.g. Nam et al., 2012; Cesana and Chepfer, 2012; Kay et al., 2012; Klein et al., 2013; Tsushima et al., 2013; Gordon and Klein, 2014; Lin et al., 2014; Bodas-Salcedo et al., 2014; Bellomo and Clement, 2015), but also in quantifying the contributions of different cloud types to cloud feedbacks and forcing adjustments in climate change experiments (e.g. Zelinka et al.,
2013, 2014; Chepfer et al., 2014; Tsushima et al., 2016). For a full list of studies that use COSP diagnostics for model evaluation and feedback analysis, please refer to the "CFMIP publications" section of the CFMIP website.

Here we will give only a brief overview of the COSP request; readers interested in the complete details of the data request are referred to the Earth System CoG website (https://www.earthsystemcog.org/projects/wip/ CMIP6DataRequest). The COSP data request for CMIP DECK and CMIP6 has been designed to span model evaluation across different space scales and timescales. Monthly mean diagnostics allow for the evaluation and intercomparison of large-scale distributions of cloud properties and their interaction with radiation. High-frequency model outputs (daily, 3-hourly) are aimed at a process-oriented evaluation (e.g. Bodas-Salcedo et al., 2012) and offer the opportunity to exploit the synergy between multiple instruments (e.g. Konsta et al., 2015). Recent observational developments have improved our ability to retrieve cloud-radiative properties. In particular, new methodologies for cloud-phase identification are available for CALIPSO and MODIS, and COSP has been enhanced to provide diagnostics that are compatible with these new observational datasets (Cesana and Chepfer, 2013). These new diagnostics will help elucidate some open questions regarding the role of cloud phase in model biases (Ceppi et al., 2016; Bodas-Salcedo et al., 2016).

Within CFMIP-3/CMIP6, COSP output is requested from six simulators as follows.

- ISCCP: pseudo-retrievals of cloud top pressure (CTP) and cloud optical thickness (tau) (Klein and Jakob, 1999; Webb et al., 2001).

- CloudSat: a forward model for radar reflectivity as a function of height (Haynes et al., 2007).

- CALIPSO (Chepfer et al., 2008; Cesana and Chepfer, 2013): forward model for the lidar scattering ratio as a function of height and cloud-phase retrieval.

- MODIS: pseudo-retrievals of CTP, effective particle size and tau as a function of phase (Pincus et al., 2012).

- MISR: pseudo-retrievals of cloud top height $(\mathrm{CTH})$ and tau (Marchand and Ackerman, 2010).

- PARASOL: simple forward model of mono-directional reflectance (Konsta et al., 2015).

The main difference to CFMIP-2 is that output is requested from a greater number of simulators and longer periods of simulated time. MISR provides more accurate retrievals of cloud-top height for low-level and mid-level clouds, and more reliable discrimination of mid-level clouds from other clouds, while MODIS provides better retrievals of highlevel clouds. ISCCP and MISR histograms can be combined to separate optically thin high-level clouds into multilayer and single-layer categories (Marchand et al., 2010). 
Aerosol schemes are becoming more complex, with more elaborate representations of cloud-aerosol interactions. This makes the evaluation of the phase partitioning an important aspect of model evaluation, and height-resolved partitioning estimates from the CALIPSO simulator are included in the COSP request. Cloud phase and particle size estimates from the MODIS simulator were not available in CFMIP-2, but may prove a useful complement to investigate cloud-aerosol interactions by virtue of greater geographic sampling and longer time records. Many of the COSP diagnostics are now requested for the entire lengths of the DECK, CMIP6 Historical and CFMIP-3/CMIP6 experiments to support the quantification and interpretation of cloud feedbacks and cloud adjustments in a broader context. The new inclusion in this COSP request of a long time series of 3-D cloud fractions will facilitate the comparison of cloud trends with the observational record (Chepfer et al., 2014). More details of all the changes with respect to CFMIP-2/CMIP5 can be found in the proposal of the CMIP6-Endorsed MIPs, available from the CMIP6 website (http://www.wcrp-climate.org/wgcm-cmip/ wgcm-cmip6).

The COSP output is in six variable groups.

- cfMon_sim: monthly means of ISCCP 2-D diagnostics (cloud fraction, cloud albedo, and cloud top pressure), ISCCP CTP-tau histogram, and CALIPSO 2-D and 3-D cloud fractions.

- cfDay_2d: daily means of ISCCP and CALIPSO 2-D diagnostics, and PARASOL reflectances.

- cfDay_3d: daily means of ISCCP and CALIPSO 3-D diagnostics.

- cfMonExtra: monthly means of CloudSat reflectitivity and CALIPSO scattering ratio histograms as a function of height, CALIPSO 3-D cloud fractions by phase, MODIS 2-D cloud fractions, MODIS CTP-tau histogram and size-tau histograms by phase, MISR CTHtau histograms, and PARASOL reflectances.

- cfDayExtra: daily means of CALIPSO total cloud fraction, MODIS CTP-tau histogram and size-tau histograms by phase, and PARASOL reflectances.

- cf3hrSim: 3-hourly instantaneous diagnostics of ISCCP CTP-tau histograms, MISR CTH-tau histograms, MODIS CTP-tau histograms and size-tau histograms by phase, CALIPSO 2-D and 3-D cloud fractions, CloudSat reflectitivity and CALIPSO scattering ratio histograms as a function of height, and PARASOL reflectances.

The variable groups cfMon_sim and cfDay_2d are requested for all years in the amip experiment performed as part of the DECK and the CMIP6 Historical experiments, and for 140 years of piControl, 1pctCO2, and abrupt-4xCO2. These are requested for one ensemble member only from these experiments. They are also requested in all of the CFMIP3/CMIP6 experiments listed in Sects. 2.1-2.6 above. cfDay_3d is requested in one ensemble member of the DECK amip experiment and in the CFMIP-3/CMIP6 amip-p $4 K$ and amip-4xCO2 experiments. cfMonExtra and cfDayExtra are requested for all years of one ensemble member of the AMIP DECK experiment, and cf3hrSim for the year 2008 only. (Please note that in the full data request these variable groups are in many cases split into a number of sub-tables. As noted above, the formal data request provides the definitive specification of the model outputs.)

COSP is available via the CFMIP website (https://www. earthsystemcog.org/projects/cfmip). Version 1.4 is a stable code release that was made available well in advance of CMIP6 at the request of the modelling groups. Small updates are required to enable some new diagnostics requested by CFMIP-3/CMIP6, most notably joint histograms of particle size and optical thickness from the MODIS simulator; with these updates the code is known as version 1.4.1. Modelling centres are encouraged to update to COSP 1.4.1 to provide these new diagnostics, but may provide results from COSP 1.4 .

Developed over the last few years, COSP 2 substantially revises the infrastructure for integrating satellite simulators in climate models. COSP 2 makes many fewer inherent assumptions about the model representation of clouds than do previous versions but contains an optional interface allowing it to be used as a drop-in replacement for COSP 1.4 or COSP 1.4.1. At the time of this writing COSP 2 is undergoing final testing in two climate models. Availability of the final version will be announced on the CFMIP website and modelling groups are free to adopt it for use in CFMIP at that time.

The CFMIP community has developed a set of observational datasets available via the CFMIP-OBS website (http: //climserv.ipsl.polytechnique.fr/cfmip-obs/) that are defined consistently with the COSP diagnostics and the CFMIP3/CMIP6 data request in terms of vertical grids and time averaging periods. These are mostly reported as monthly means, although some are reported at a higher temporal resolution for process oriented model evaluations (e.g. Konsta et al., 2012). Table 3 summarizes the datasets relevant to the COSP CMIP6 data request. Some of the CFMIPOBS datasets listed in Table 3 (CALIPSO, CloudSat, ISCCP, PARASOL) are also available from the ESGF as part of the obs4MIPs project (Teixeira et al., 2014). These datasets are periodically updated to include more recent data from the relevant satellites, many of which are still operational. Please refer to the CFMIP-OBS website for updates.

\subsection{Monthly mean diurnal cycle outputs}

Climate models have difficulties representing the diurnal cycle of convective clouds over land (Yang and Slingo, 2001; 
Table 3. Summary of CFMIP-OBS observational datasets available for comparison with COSP diagnostics.

\begin{tabular}{|c|c|c|c|c|}
\hline Dataset & Years/months & Observables & Applications & References \\
\hline CALIPSO-GOCCP & 2006/06-2012/10 & $\begin{array}{l}\text { Cloud fractions: 2-D and 3-D } \\
\text { by phase } \\
\text { Scattering ratio histograms as a } \\
\text { function of height }\end{array}$ & $\begin{array}{l}\text { Vertical distributions of clouds. } \\
\text { Cloud-phase identification }\end{array}$ & $\begin{array}{l}\text { Chepfer et al. (2010), Cesana } \\
\text { and Chepfer (2013) }\end{array}$ \\
\hline CloudSat & 2006/06-2010/12 & $\begin{array}{l}\text { Reflectivity histograms as a } \\
\text { function of height }\end{array}$ & $\begin{array}{l}\text { Vertical distributions of clouds } \\
\text { and precipitation }\end{array}$ & $\begin{array}{l}\text { Marchand et al. (2009), Zhang } \\
\text { et al. (2010) }\end{array}$ \\
\hline ISCCP & 1983/07-2008/06 & $\begin{array}{l}\text { Cloud top pressure - cloud op- } \\
\text { tical depth histograms }\end{array}$ & $\begin{array}{l}\text { Cloud-radiative } \\
\text { Long time series }\end{array}$ & Rossow and Schiffer (1999) \\
\hline MODIS & 2002/07-2015/11 & $\begin{array}{l}\text { Cloud top pressure - cloud op- } \\
\text { tical depth histograms } \\
\text { Total, liquid and ice cloud frac- } \\
\text { tions } \\
\text { Effective radius - optical depth } \\
\text { histograms by cloud phase }\end{array}$ & $\begin{array}{l}\text { Cloud-radiative properties. Ef- } \\
\text { fective size and phase informa- } \\
\text { tion }\end{array}$ & $\begin{array}{l}\text { Pincus et al. (2012), King et } \\
\text { al. (2003) }\end{array}$ \\
\hline MISR & 2000/06-2013/05 & $\begin{array}{l}\text { Cloud top height }(\mathrm{CTH})-\text { cloud } \\
\text { optical depth histograms }\end{array}$ & $\begin{array}{l}\text { Cloud-radiative properties. In- } \\
\text { dependent estimate of cloud top } \\
\text { height }\end{array}$ & Marchand et al. (2010) \\
\hline PARASOL & $2003 / 05-2012 / 08$ & Monodirectional reflectance & Cloud-radiative properties & Konsta et al. (2015) \\
\hline
\end{tabular}

Stratton and Stirling, 2011), but its evaluation is not possible with sun-synchronous satellites. Geostationary satellites provide high-frequency sampling that can be used to evaluate model biases in the diurnal cycle of clouds and radiation (albeit over a limited area). The Geostationary Earth Radiation Budget instrument (GERB; Harries et al., 2005) measures the top of atmosphere (TOA) radiation budget from a geostationary orbit at $0^{\circ} \mathrm{E}$ at $15 \mathrm{~min}$ frequency, which provides a unique view of tropical convection over Africa. The variable group cflhrClimMon requests monthly mean diurnal cycle of TOA radiative fluxes (all-sky and clear-sky) for the entire length of the AMIP DECK experiment. The radiative fluxes are hourly UTC means. The "average day" for each month of the simulation is then constructed by averaging each UTC hourly mean over the entire month. These diagnostics will be directly comparable with GERB measurements.

\section{Summary}

The primary goal of CFMIP is to inform improved assessments of cloud feedbacks on climate change. This involves bringing climate modelling, observational and process modelling communities closer together and providing better tools and community support for understanding and evaluation of clouds and cloud feedbacks simulated by climate models. CFMIP supports ongoing coordinated model inter-comparison activities by recommending experiments and model output diagnostics for CMIP, designed to support the understanding and evaluation of cloud processes and cloud feedbacks in models. The CFMIP approach is also increasingly being used to understand other aspects of climate change, and so a second objective has now been introduced, to improve understanding of circulation, regional-scale precipitation, and non-linear changes. CFMIP proposes a number of CFMIP-3/CMIP6 experiments and model outputs for CMIP6, building on and extending those which were part of CFMIP-2/CMIP5.

A compact set of CFMIP-3/CMIP6 Tier 1 experiments are proposed to address the question (1) What are the physical mechanisms underlying the range of cloud feedbacks and cloud adjustments predicted by climate models, and which models have the most credible cloud feedbacks? The Tier 1 experiments (amip-p4K, amip-4xCO2, amip-future $4 K$, aquacontrol, aqua- $4 x \mathrm{CO} 2$ and aqua-p $4 K$ ) retain the idealized experimental hierarchy of the CFMIP-2/CMIP5 experiments while building on the DECK amip experiment. A number of Tier 2 experiments are proposed to address additional science questions. An amip uniform minus $4 \mathrm{~K}$ experiment is proposed to address the question (2) Are cloud feedbacks consistent for climate cooling and warming, and if not, why? Atmosphere-only experiments with clouds made transparent to longwave radiation address the question (3) How do cloudradiative effects impact the structure, the strength and the variability of the general atmospheric circulation in present and future climates? Abrupt $\pm 4 \%$ Solar Forced AOGCM experiments are proposed for the question (4) How do responses in the climate system due to changes in solar forcing differ from changes due to $\mathrm{CO}_{2}$, and is the response sensitive to the sign of the solar forcing? Abrupt $2 \times \mathrm{CO}_{2}$ and abrupt $0.5 \times \mathrm{CO}_{2}$ experiments are proposed to address the question (5) To what extent is regional-scale climate change per $\mathrm{CO}_{2}$ doubling state-dependent (non-linear), and why? An amip 
experiment with pre-industrial forcing addresses this question: (6) are climate feedbacks during the 20th century different to those acting on long-term climate change and climate sensitivity? Time slice experiments forced with SSTs from pre-industrial and abrupt-4xCO2 simulations address this question: (7) how do regional climate responses (of e.g. precipitation) in a coupled model arise from the combination of responses to different aspects of $\mathrm{CO}_{2}$ forcing and warming (uniform SST warming, pattern SST warming, direct $\mathrm{CO}_{2}$ effect, plant physiological effect, sea-ice change)?

The CFMIP-3/CMIP6 experiments will continue to include outputs from the CFMIP Observational Simulator Package (COSP) to support robust scale-aware and definition-aware evaluation of modelled clouds with observations and to relate cloud feedbacks to observed quantities. COSP outputs are also proposed for inclusion in the DECK and CMIP6 Historical experiments. Process diagnostics, including "cfSites" high-frequency outputs at selected locations and temperature and humidity budget terms from radiation, convection, dynamics, etc., are also retained from CFMIP-2/CMIP5. These will help to address the following questions.

1. How well do clouds and other relevant variables simulated by models agree with observations?

2. What physical processes and mechanisms are important for a credible simulation of clouds, cloud feedbacks and cloud adjustments in climate models?

3. Which models have the most credible representations of processes relevant to the simulation of clouds?

4. How do clouds and their changes interact with other elements of the climate system?

By continuing the CFMIP-2/CMIP5 experiments and diagnostic outputs within CFMIP-3/CMIP6 we hope to apply the well-established aspects of the CFMIP approach to a larger number of climate models. Additionally we have proposed new CFMIP-3/CMIP6 experiments to investigate a broader range of questions relating to the Grand Challenge on Clouds, Circulation and Climate Sensitivity. We hope that the modelling community will participate fully in CFMIP-3 via CMIP6 so as to maximize the relevance of our findings to future assessments of climate change.

\section{Code and data availability}

COSP is published under an open-source license via GitHub (please see the CFMIP website for details). The model output from the DECK, CMIP6 Historical and CFMIP3/CMIP6 simulations described in this paper will be distributed through the Earth System Grid Federation (ESGF) with digital object identifiers (DOIs) assigned. As in CMIP5, the model output will be freely accessible through data portals after registration. In order to document CMIP6's scientific impact and enable ongoing support of CMIP, users are obligated to acknowledge CMIP6, the participating modelling groups, and the ESGF centres (see details on the CMIP Panel website at http://www.wcrp-climate.org/index. $\mathrm{php} / \mathrm{wgcm}$-cmip/about-cmip). Further information about the infrastructure supporting CMIP6, the metadata describing the model output, and the terms governing its use are provided by the WGCM Infrastructure Panel (WIP) in their invited contribution to this Special Issue. Along with the data themselves, the provenance of the data will be recorded, and DOIs will be assigned to collections of output so that they can be appropriately cited. This information will be made readily available so that published research results can be verified and credit can be given to the modelling groups providing the data. The WIP is coordinating and encouraging the development of the infrastructure needed to archive and deliver this information. In order to run the experiments, datasets for natural and anthropogenic forcings are required. These forcing datasets are described in separate invited contributions to this Special Issue. The forcing datasets will be made available through the ESGF with version control and DOIs assigned. 


\section{Appendix A: Analysis plan and CFMIP Diagnostic Codes Catalogue}

CFMIP-2 analysis activities are ongoing and the CFMIP community is ready to analyse CFMIP-3/CMIP6 data at any time. We would like modelling groups to perform the proposed CFMIP-3/CMIP6 experiments at the same time or shortly after their DECK and CMIP6 Historical experiments. Subsequent informally organized CFMIP-3 experiments which are not included in CMIP6 will build on the proposed DECK and CFMIP-3/CMIP6 experiments and some will start as soon as CMIP6 DECK experiments start to become available. We envisage a succession of CFMIP-related intercomparisons addressing different questions arising from the Grand Challenge spanning the duration of CMIP6.

We plan to scientifically analyse, evaluate and exploit the proposed experiments and diagnostic outputs, and have identified lead coordinators within CFMIP for different aspects of this activity. The lead coordinators are responsible for encouraging analysis of the relevant experiments as broadly as possible across the scientific community. While they may lead some analysis themselves, they do not have any first claim on analysing or publishing the results. All interested investigators are encouraged to exploit the data from these experiments. While investigators may wish to liaise with the lead coordinators to avoid duplicating work that others are doing, this is not a requirement. An overview of the proposed evaluation/analysis of the CMIP DECK, CMIP6 Historical and CFMIP-3/CMIP6 experiments follows.

CFMIP will continue to exploit the CMIP DECK and CMIP6 experiments to understand and evaluate cloud processes and cloud feedbacks in climate models. The wide range of analysis activities described above in the context of CFMIP-2 will be continued in CFMIP-3 using the CMIP DECK and CFMIP-3/CMIP6 experiments, allowing the techniques developed in CFMIP-2 to be applied to an expanding number of models, including the new generation of models currently under development. These activities will include evaluation of clouds using additional simulators, investigation of cloud processes and cloud feedback/adjustment mechanisms using process outputs (cfSites, tendency terms, etc.). The inclusion of COSP and budget tendency terms in additional DECK experiments (e.g. abrupt-4xCO2) will enable the CFMIP approach to be applied to a wider range of experimental configurations. Lead coordinator: Mark Webb.

Analysis of the $\pm 4 \%$ solar forcing runs will include an evaluation of both rapid adjustments and longer-term responses to global and regional top-of-atmosphere radiative fluxes, cloud types (using ISCCP and other COSP simulators) and precipitation characteristics, as well as comparison of these responses with responses in DECK abrupt$4 x \mathrm{CO} 2$ experiments. GeoMIP and SolarMIP have expressed a strong interest in these CFMIP-3/CMIP6 experiments and joint analysis of these experiments with GeoMIP and SolarMIP experiments is anticipated, specifically with the goal of determining to what degree results from abrupt solar forcing only experiments and abrupt $\mathrm{CO}_{2}$ only experiments can be used to predict what happens when both forcing are applied simultaneously, as done in the GeoMIP experiments. Lead coordinators: Chris Bretherton, Roger Marchand and Bjorn Stevens.

Analysis of non-linear climate processes is discussed in detail by Good et al. (2016). This includes a method for validating traceability of abrupt $\mathrm{CO}_{2}$ experiments to transient simulations, which is also recommended as a standard test of the DECK abrupt-4xCO2 experiment. Analysis will primarily involve comparing the abrupt-4xCO2, abrupt-2xCO2 and abrupt-0p5xCO2 experiments over the same timescale. Lead coordinator: Peter Good.

Analysis of amip-piForcing has already been performed in detail for two models in Andrews (2014) and Gregory and Andrews (2016). We propose using this as a starting point for a multi-model analysis. Lead coordinator: Timothy Andrews.

An overview analysis of regional responses and model uncertainty in the piSST set of experiments will be carried out by the coordinators, in collaboration with members of contributing modelling groups. We anticipate that further detailed analysis on the processes at work in different regions will be carried out by a variety of research groups with interest and expertise in a particular region: for example, a set of similar experiments has previously been used to examine the climate response of the West African monsoon in CCSM3 (Skinner et al., 2012). The piSST set of experiments has already been successfully run using the Met Office, NCAR and CNRM CMIP5 models. Lead coordinators: Robin Chadwick, Hervé Douville and Christopher Skinner.

The analysis of the COOKIE experiments will be reviewed by the coordinators in collaboration with members of the contributing modelling groups. The role of longwave atmospheric cloud-radiative effects in large-scale circulations, regional precipitation patterns and the organization of tropical convection will be investigated in the current climate and in climate change, with the aim of highlighting both robust effects and sources of uncertainties in the model responses. Lead coordinators: Sandrine Bony and Bjorn Stevens.

When analysed together with the amip- $p 4 K$ experiment, the amip- $m 4 K$ experiment allows the CFMIP process diagnostics to be used to understand for asymmetries in the climate response to warming and cooling which have been noted in PMIP experiments. These might arise from cloudphase responses in middle- and high-latitude clouds or from the adiabatic cloud liquid water path response feedback which is important over land regions and which would be expected to be weaker with cooling because of the non-linearity in the Clausius-Clapeyron relation. Lead coordinators: Mark Webb and Bjorn Stevens.

The COSP data request for the AMIP DECK experiment will allow a comprehensive multi-model evaluation of clouds and radiation, following on from CMIP5 studies (e.g. Klein et al., 2013; Bodas-Salcedo et al., 2014). The COSP data 
request for the other experiments (e.g. amip-p4K, abrupt$4 x \mathrm{CO} 2)$ permits evaluation of cloud feedbacks and adjustments by cloud type (Zelinka et al., 2013; Tsushima et al., 2016) or cloud trends (Chepfer et al., 2014). New COSP diagnostics have been used in single-model analyses: cloudphase diagnostics (Cesana and Chepfer, 2013); MISR simulator outputs to evaluate cloud fraction and multi-layer clouds (Marchand and Ackerman, 2010); and CALIPSO vertical distribution of cloud fraction for the study of cloud trends (Chepfer et al., 2014). These studies will be used as starting points for multi-model analyses. The COSP Project Management Committee co-chairs will coordinate and encourage the exploitation of these resources. Lead coordinators: Alejandro Bodas-Salcedo and Steve Klein.

Analysis of output from the CFMIP-3/CMIP6 and CMIP DECK experiments will also be facilitated by sharing of diagnostic codes via the CFMIP Diagnostics Code Catalogue (accessible via the CFMIP website: http://www. earthsystemcog.org/projects/cfmip/). This is a catalogue of programs written by various members of the CFMIP community, implementing a number of diagnostic approaches from published studies. These include daily cloud clustering evaluation metrics based on ISCCP and ISCCP simulator outputs (Williams and Webb, 2009; Tsushima et al., 2013), error metrics for total cloud amount, longwave and shortwave cloud properties (Klein et al., 2013), process oriented evaluation of clouds using A-train instantaneous observations (Konsta et al., 2012), quality control and low-cloud diagnostics (Nam et al., 2012; Nam and Quaas, 2012), sensitivity of low cloud cover to estimated inversion strength and SST (Qu et al., 2014) and cloud-radiative kernels (Zelinka et al., 2012b). Any codes which implement diagnostics which are relevant to analysing clouds, circulation and climate sensitivity in models and which are documented in peer-reviewed studies are eligible for inclusion in the catalogue, and we welcome additional contributions to further support community analysis of CMIP6 outputs.

\section{Appendix B: Aquaplanet experimental design}

Aquaplanets are Earth-like planets with completely watercovered surfaces. They are often used as idealized configurations of atmospheric GCMs, and in this context the usual convention is that land masses and topography are removed. Although many flavours of aquaplanet configurations exist, another convention is to retain as much of the atmospheric model's formulation as possible. That is, the numerical grid, dynamical core, and parameterized physics are all used just as in realistic climate simulations.

The Tier 1 aquaplanet experiments follow the same experimental design as CFMIP-2/CMIP5 (Medeiros et al., 2015). Those, in turn, were closely related to previous aquaplanet descriptions. In particular, the control configuration closely follows the AquaPlanet Experiment protocol (Blackburn and
Hoskins, 2013) using a prescribed SST pattern described by Neale and Hoskins (2000). Two additional runs paralleled the CFMIP-2/CMIP5 amip $4 \mathrm{~K}$ and amip $4 x \mathrm{CO} 2$ experiments: a uniform $4 \mathrm{~K}$ warming and a quadrupling of atmospheric $\mathrm{CO}_{2}$.

Here we provide the detailed experimental protocol for the three aquaplanet simulations that are part of Tier 1 . We note again that these follow the APE protocol and CFMIP2/CMIP5, and therefore largely mirror previous descriptions in Blackburn and Hoskins (2013), Williamson et al. (2012), and Medeiros et al. (2015).

Orbital parameters are set to perpetual equinox conditions. This is usually achieved by setting eccentricity and obliquity to zero to define a circular orbit and insolation independent of calendar. The diurnal cycle is retained. Insolation is based on a non-varying solar constant of $1365 \mathrm{~W} \mathrm{~m}^{-2}$.

The SST is non-varying and zonally uniform. The longitudinal variation is specified using the "Qobs" SST pattern from Neale and Hoskins (2000), given by

$T(\varphi)=$
$\left\{\begin{array}{c}\frac{1}{2}\left(2-\sin ^{4} \phi-\sin ^{2} \phi\right) \delta T+T_{\min }, \text { if }|\varphi|<\frac{\pi}{3} \\ 0, \text { otherwise }\end{array}\right.$

where $\varphi$ is latitude, $\phi=\frac{\pi}{2} \frac{\varphi}{\varphi_{\max }}, \varphi_{\max }=\frac{\pi}{3}, \delta T=T_{\max }-$ $T_{\min }, T_{\max }=27^{\circ} \mathrm{C}$, and $T_{\min }=0^{\circ} \mathrm{C}$.

Because results are sensitive to the specification of the SSTs, groups that use a prognostic equation for the surface skin temperature are asked to set this skin temperature to the specified SST. No sea ice is prescribed, so the surface temperature is spatially uniform at $0^{\circ} \mathrm{C}$ poleward of $60^{\circ} \mathrm{C}$ for the control simulation.

Radiatively active trace gases are well mixed, with mixing ratios following the AMIP II recommendations: $\mathrm{CO}_{2}$ : 348 ppmv; $\mathrm{CH}_{4}$ : 1650 ppbv; $\mathrm{N}_{2} \mathrm{O}: 306$ ppbv; halocarbon yield of approximately $0.24 \mathrm{~W} \mathrm{~m}^{-2}$ radiative forcing. The ozone distribution is the same as used in APE and CFMIP2/CMIP5, is derived from the climatology used in AMIP II (Gates et al., 1999), and is constant in time and symmetric zonally and about the Equator. This ozone distribution is provided as a netCDF file which is archived on the Earth System Grid and available via the DOI http://dx.doi.org/10.5065/ D61834Q6. Ozone values are provided up to $0.28 \mathrm{hPa}$ (about $60 \mathrm{~km}$ altitude in mid-latitudes). For models with tops above this level, a high top ozone dataset is also provided, which is available via the DOI http://doi.org/10.5065/D64X5653. The ozone climatologies provided use pressure as a vertical coordinate. Most models use a sigma or hybrid vertical coordinate in pressure or altitude, which will mean that the pressure on a given model level varies in time, near the surface at the very least. Although the ozone climatology can be interpolated to the pressure of each model level as it varies in time within the model, for simplicity we recommend interpolating the ozone dataset onto the model vertical grid before the 
experiment is performed, and then specifying ozone values which are constant in time on each model level. This vertical interpolation will require a zonally symmetric climatology of pressure on model levels which is as consistent as possible with that expected in the aqua-control experiment. This could for example be produced by initially running a test version of the aqua-control experiment with an ozone climatology taken from a more realistic model configuration such as the AMIP DECK experiment.

Aerosols are removed to the extent possible to remove aerosol-radiation interaction (aka direct effects) and aerosolcloud interaction (aka indirect effects). No external surface emissions are to be prescribed. Models requiring aerosol for cloud condensation should use a constant oceanic climatology that is symmetric about the Equator and zonally. Alternatively, models with the capability should set the cloud droplet and crystal numbers to $100 \times 10^{6}$ and $0.1 \times 10^{6} \mathrm{~m}^{-3}$, respectively (as in Medeiros et al., 2016).

As in APE, it is recommended that the atmospheric dry mass be adjusted to yield a global mean of $101080 \mathrm{~Pa}$. It is also recommended to adopt the APE recommended values for geophysical constants, as listed in Table 2 of Williamson et al. (2012).

The aqua- $4 K$ experiment follows the above protocol, but with SST derived by adding $4 \mathrm{~K}$ to Eq. (B1).

The aqua-4xCO2 experiment replaces the $\mathrm{CO}_{2}$ mixing ratio with $1392 \mathrm{ppmv}$. The SST is unchanged from the control simulation (Eq. B1).

Model runs should be 10 years. We recommend discarding the initial spin-up period of a few months.

\section{Appendix C: SST pattern for CFMIP-3/CMIP6 amip-future4K/amipFuture experiments}

The amip-future $4 K$ (formerly amipFuture) experiment is the same as the AMIP DECK experiment, except that the SSTs are subject to a composite SST warming pattern derived from the CMIP3 coupled models. The patterned SST forcing dataset is available in a netcdf file called cfmip2_4k_patterned_sst_forcing.vn1.0.nc which is available in the Supplement for this paper, and via the CFMIP website. This is a normalized multi-model ensemble mean of the ocean surface temperature response pattern (the change in ocean surface temperature (TOS) between years 0-20 and $140-160$, the time of CO2 quadrupling in the $1 \%$ runs) from 13 CMIP3 AOGCMs (cccma, cnrm, gfdlcm20, gfdlcm21, gisser, inmcm3, ipsl, miroc-medres, miub, mpi, mri, ncarccsm3, and ncar-pcm1). Before computing the multi-model ensemble mean, each model's TOS response was divided by its global mean and multiplied by 4 . This guarantees that the pattern information from all models is weighted equally and that the global mean SST forcing is the same as in the uniform $+4 \mathrm{~K}$ experiment. We have retained the SST forcing based on the CMIP3 coupled models because we consider it more important to be able to compare CMIP5 and CMIP6 models forced with the same SST pattern than to use a pattern which is consistent with, say, the CMIP5 coupled response. 


\section{The Supplement related to this article is available online at doi:10.5194/gmd-10-359-2017-supplement.}

Acknowledgements. We are grateful to Florent Brient, Hideo Shiogama, Aiko Voigt, Mark Ringer and two anonymous referees for helpful comments on the manuscript. We thank the modelling groups and the wider CFMIP community for reviewing and supporting the CFMIP contribution to CMIP6, the CMIP Panel for their coordination of CMIP6, the WGCM Infrastructure Panel (WIP) overseeing the CMIP6 infrastructure, and Martin Juckes for taking the lead in preparing the CMIP6 data request. We are also grateful to Robert Pincus and Yuying Zhang for their contributions to COSP and to CFMIP-OBS, to Dustin Swales for his development work for COSP-2, and to Gregory Cesana and Mathieu Reverdy for their contributions to CFMIP-OBS. We are grateful to Brian Soden for producing the CMIP3 composite pattern dataset used for the CMIP5 amipFuture and CMIP6 amip-future $4 \mathrm{~K}$ experiments, and to PMIP representatives Pascale Braconnot, Masa Kageyama, and Masakazu Yoshimori for discussions relating to the amip-m4K experiment. The efforts of S. A. Klein are supported by the Regional and Global Climate Modeling program of the United States Department of Energy's Office of Science and were performed under the auspices of the U.S. Department of Energy by Lawrence Livermore National Laboratory under contract DEAC5207NA27344. Met Office Hadley Centre authors are supported by the Joint UK BEIS DECC/Defra Met Office Hadley Centre Climate Programme (GA01101).

Edited by: J. Hargreaves

Reviewed by: A. Voigt and two anonymous referees

\section{References}

Andrews, T.: Using an AGCM to diagnose historical effective radiative forcing and mechanisms of recent decadal climate change, J. Climate, 27, 1193-1209, doi:10.1175/JCLI-D-13-00336.1, 2014.

Andrews, T. and Forster, P. M.: $\mathrm{CO}_{2}$ forcing induces semi-direct effects with consequences for climate feedback interpretations, Geophys. Res. Lett., 35, L04802, doi:10.1029/2007GL032273, 2008.

Andrews, T., Forster, P. M., Boucher, O., Bellouin, N., and Jones, A.: Precipitation, radiative forcing and global temperature change, Geophys. Res. Lett., 37, L14701, doi:10.1029/2010GL043991, 2010.

Andrews, T., Gregory, J. M., Webb, M. J., and Taylor, K. E.: Forcing, feedbacks and climate sensitivity in CMIP5 coupled atmosphere-ocean climate models, Geophys. Res. Lett., 39, L09712, doi:10.1029/2012GL051607, 2012.

Andrews, T., Gregory, J. M., and Webb, M. J.: The dependence of radiative forcing and feedback on evolving patterns of surface temperature change in climate models, J. Climate, 28, 16301648, doi:10.1175/JCLI-D-14-00545.1, 2015.

Aqua-Planet Experiment Project Ozone Dataset, doi:10.5065, D61834Q, Publisher Ilana Stern.

Aqua-Planet Experiment Project Ozone High-Top Extension, doi:10.5065/D64X5653, Publisher Ilana Stern.
Armour, K. C., Bitz, C. M., and Roe, G. H.: Time-varying climate sensitivity from regional feedbacks, J. Climate, 26, 4518-4534, 2013.

Bellomo, K. and Clement, A. C.: Evidence for weakening of the Walker circulation from cloud observations, Geophys. Res. Lett., 42, 7758-7766, 2015.

Bellomo, K., Clement, A. C., Mauritsen, T., Radel, G., and Stevens, B.: The Influence of Cloud Feedbacks on Equatorial Atlantic Variability, J. Climate, 28, 2725-2744, 2015.

Bergman, J. W. and Hendon, H. H.: Cloud radiative forcing of the low-latitude tropospheric circulation: Linear calculations, J. Atmos. Sci., 57, 2225-2245, 2000.

Blackburn, M. and Hoskins, B. J.: Context and aims of the Aqua-Planet Experiment, J. Meteorol. Soc. Jpn., 91A, 1-15, doi:10.2151/jmsj.2013-A01, 2013.

Block, K. and Mauritsen, T.: Forcing and feedback in the MPIESM-LR coupled model under abruptly quadrupled $\mathrm{CO}_{2}$, J. Adv. Model. Earth Syst., 5, 676-691, doi:10.1002/jame.20041, 2013.

Blossey, P. N., Bretherton, C. S., Zhang, M., Cheng, A., Endo, S., Heus, T., Liu, Y., Lock, A. P., Roode, S. R., and Xu, K. M.: Marine low cloud sensitivity to an idealized climate change: The CGILS LES intercomparison, J. Adv. Model. Earth Syst., 5, 234 258, 2013.

Bodas-Salcedo, A., Webb, M. J., Brooks, M. E., Ringer, M. A., Williams, K. D., Milton, S. F., and Wilson, D. R.: Evaluating cloud systems in the Met Office global forecast model using simulated CloudSat radar reflectivities, J. Geophys. Res.-Atmos., 113, D00A13, doi:10.1029/2007JD009620, 2008.

Bodas-Salcedo, A., Webb, M. J., Bony, S., Chepfer, H., Dufresne, J. L., Klein, S. A., Zhang, Y., Marchand, R., Haynes, J. M., Pincus, R., and John, V. O.: COSP: Satellite simulation software for model assessment, B. Am. Meteorol. Soc., 92, 1023, doi:10.1175/2011BAMS2856.1, 2011.

Bodas-Salcedo, A., Williams, K. D., Field, P. R., and Lock, A. P.: The surface downwelling solar radiation surplus over the Southern Ocean in the Met Office model: The role of midlatitude cyclone clouds, J. Climate, 25, 7467-7486, doi:10.1175/JCLI-D11-00702.1, 2012.

Bodas-Salcedo, A., Williams, K. D., Ringer, M. A., Beau, I., Cole, J. N., Dufresne, J. L., Koshiro, T., Stevens, B., Wang, Z., and Yokohata, T.: Origins of the solar radiation biases over the Southern Ocean in CFMIP2 models, J. Climate, 27, 41-56, doi:10.1175/JCLI-D-13-00169.1, 2014.

Bodas-Salcedo, A., Hill, P. G., Furtado, K., Williams, K. D., Field, P. R., Manners, J. C., Hyder, P., and Kato, S.: Large contribution of supercooled liquid clouds to the solar radiation budget of the Southern Ocean, J. Climate, 29, 4213-4228, doi:10.1175/JCLID-15-0564.1, 2016.

Bony, S. and Dufresne, J. L.: Marine boundary layer clouds at the heart of tropical cloud feedback uncertainties in climate models, Geophys. Res. Lett., 32, L20806, doi:10.1029/2005GL023851, 2005.

Bony, S., and Emanuel, K. A.: On the role of moist processes in tropical intraseasonal variability: Cloud-radiation and moisture-convection feedbacks, J. Atmos. Sci., 62, 2770, doi:10.1175/JAS3506.1, 2015.

Bony, S., Webb, M., Bretherton, C. S., Klein, S. A., Siebesma, P., Tselioudis, G., and Zhang, M.: CFMIP: Towards a better evalua- 
tion and understanding of clouds and cloud feedbacks in CMIP5 models, Clivar Exchanges, 56, 20-22, 2011.

Bony, S., Bellon, G., Klocke, D., Sherwood, S., Fermepin, S., and Denvil, S.: Robust direct effect of carbon dioxide on tropical circulation and regional precipitation, Nat. Geosci., 6, 447-451, doi:10.1038/ngeo1799, 2013

Bony, S., Stevens, B., Frierson, D. M., Jakob, C., Kageyama, M., Pincus, R., Shepherd, T. G., Sherwood, S. C., Siebesma, A. P., Sobel, A. H., and Watanabe, M.: Clouds, circulation and climate sensitivity, Nat. Geosci., 8, 261-268, 2015.

Boucher, O., Randall, D., Artaxo, P., Bretherton, C. S., Feingold, G., Forster, P. M., Kerminen, V.-M., Kondo, Y., Liao, H., Lohmann, U., Rasch, P., Satheesh, S. K., Sherwood, S., Stevens, B., and Zhang, X.-Y.: Clouds and Aerosols, in: Climate change 2013: The physical science basis. Contribution of working group I to the fifth assessment report of the intergovernmental panel on climate change, Cambridge University Press, 571-657, 2013.

Bouttes, N., Good, P., Gregory, J. M., and Lowe, J. A.: Nonlinearity of ocean heat uptake during warming and cooling in the famous climate model, Geophys. Res. Lett., 42, 2409-2416, doi:10.1002/2014GL062807, 2015.

Bretherton, C. S.: Insights into low-latitude cloud feedbacks from high-resolution models, Phil. Trans. R. Soc. A, 373, 2054, doi:10.1098/rsta.2014.0415, 2015.

Bretherton, C. S., Blossey, P. N., and Stan, C.: Cloud feedbacks on greenhouse warming in the superparameterized climate model SP-CCSM4, J. Adv. Model. Earth Syst., 6, 1185-1204, 2014.

Brient, F. and Bony, S.: How may low-cloud radiative properties simulated in the current climate influence low-cloud feedbacks under global warming?, Geophys. Res. Lett., 39, L20807, doi:10.1029/2012GL053265, 2012.

Brient, F. and Bony, S.: Interpretation of the positive low-cloud feedback predicted by a climate model under global warming, Clim. Dynam., 40, 2415-2431, 2013.

Brient, F., Schneider, T., Tan, Z., Bony, S., Qu, X., and Hall, A.: Shallowness of tropical low clouds as a predictor of climate models' response to warming, Clim. Dynam., 433-449, doi:10.1007/s00382-015-2846-0, 2015.

Butler, A. H., Thompson, D. W. J., and Heikes, R.: The SteadyState Atmospheric Circulation Response to Climate Change-like Thermal Forcings in a Simple General Circulation Model, J. Climate, 23, 3474-3496, 2010.

Ceppi, P., Hwang, Y.-T., Frierson, D. M. W., and Hartmann, D. L.: Southern Hemisphere jet latitude biases in CMIP5 models linked to shortwave cloud forcing, Geophys. Res. Lett., 39, L19708, doi:10.1029/2012GL053115, 2012.

Ceppi, P., Zelinka, M. D., and Hartmann, D. L.: The response of the Southern Hemispheric eddy-driven jet to future changes in shortwave radiation in CMIP5, Geophys. Res. Lett., 41, 32443250, 2014.

Ceppi, P., Hartmann, D. L., and Webb, M. J.: Mechanisms of the negative shortwave cloud feedback in mid to high latitudes, J. Climate, 29, 139-157, doi:10.1175/JCLI-D-15-0327.1, 2016.

Ceppi, P., McCoy, D. T., and Hartmann, D. L.: Observational evidence for a negative shortwave cloud feedback in middle to high latitudes, Geophys. Res. Lett., 43, 1331-1339, 2016.

Cesana, G. and Chepfer, H.: How well do climate models simulate cloud vertical structure? A comparison between CALIPSO-
GOCCP satellite observations and CMIP5 models, Geophys. Res. Lett., 39, L20803 doi:10.1029/2012GL053153, 2012.

Cesana, G. and Chepfer, H.: Evaluation of the cloud thermodynamic phase in a climate model using CALIPSO-GOCCP, J. Geophys. Res., 118, 7922-7937, doi:10.1002/jgrd.50376, 2013.

Chadwick, R.: Which Aspects of $\mathrm{CO}_{2}$ Forcing and SST Warming Cause Most Uncertainty in Projections of Tropical Rainfall Change over Land and Ocean, J. Climate, 29, 2493-2509, doi:10.1175/JCLI-D-15-0777.1, 2016.

Chadwick, R. and Good, P.: Understanding non-linear tropical precipitation responses to $\mathrm{CO}_{2}$ forcing,Geophys. Res. Lett., 40, 4911-4915, doi:10.1002/grl.50932, 2013.

Chadwick, R., Good, P., Andrews, T., and Martin, G.: Surface warming patterns drive tropical rainfall pattern responses to $\mathrm{CO}_{2}$ forcing on all timescales., Geophys. Res. Lett., 41, 610-615, doi:10.1002/2013GL058504, 2014.

Chepfer, H., Bony, S., Winker, D., Chiriaco, M., Dufresne, J.-L., and Sèze, G.: Use of CALIPSO lidar observations to evaluate the cloudiness simulated by a climate model, Geophys. Res. Lett., 35, L15704, doi:10.1029/2008GL034207, 2008.

Chepfer, H., Bony, S., Winker, D., Cesana, G., Dufresne, J.-L., Minnis, P., Stubenrauch, C. J., and Zeng, S.: The GCM Oriented CALIPSO Cloud Product (CALIPSO-GOCCP), J. Geophys. Res., 115, D00H16, doi:10.1029/2009JD012251, 2010.

Chepfer, H., Noel, V., Winker, D., and Chiriaco, M.: Where and when will we observe cloud changes due to climate warming?, Geophys. Res. Lett., 41, 8387-8395, doi:10.1002/2014GL061792, 2014

Collins, M., Knutti, R., Arblaster, J., Dufresne, J.-L., Fichefet, T., Friedlingstein, P., Gao, X., Gutowski, W. J., Johns, T., Krinner, G., Shongwe, M., Tebaldi, C., Weaver, A. J., and Wehner, M.: Long-term climate change: Projections, commitments and irreversibility, in: Climate Change 2013: The Physical Science Basis. Contribution of Working Group I to the Fifth Assessment Report of the Intergovernmental Panel on Climate Change, Cambridge University Press, edited by: Stocker, T. F., Qin, D., Plattner, G.-K., Tignor, M., Allen, S. K., Boschung, J., Nauels, A., Xia, Y., Bex, V., and Midgley, P. M., Cambridge, United Kingdom and New York, NY, USA, 1029-1136, 2013.

Colman, R. and McAvaney, B.: Climate feedbacks under a very broad range of forcing, Geophys. Res. Lett., 36, L01702, doi:10.1029/2008g1036268, 2009.

Crueger, T. and Stevens, B.: The effect of atmospheric radiative heating by clouds on the Madden-Julian Oscillation, J. Adv. Model. Earth Syst., 7, 854-864, 2015.

Dal Gesso, S., Van der Dussen, J. J., Siebesma, A. P., De Roode, S. R., Boutle, I. A., Kamae, Y., Roehrig, R., and Vial, J.: A singlecolumn model intercomparison on the stratocumulus representation in present-day and future climate, J. Adv. Model. Earth Syst., 7, 617-647, 2015.

Demoto, S., Watanabe, M., and Kamae, Y.: Mechanism of tropical low-cloud response to surface warming using weather and climate simulations, Geophys. Res. Lett., 40, 2427-2432, 2013.

Eyring, V., Bony, S., Meehl, G. A., Senior, C. A., Stevens, B., Stouffer, R. J., and Taylor, K. E.: Overview of the Coupled Model Intercomparison Project Phase 6 (CMIP6) experimental design and organization, Geosci. Model Dev., 9, 1937-1958, doi:10.5194/gmd-9-1937-2016, 2016. 
Fasullo, J. T. and Trenberth, K. E.: A less cloudy future: The role of subtropical subsidence in climate sensitivity, Science, 338, 792794, 2012.

Fermepin, S. and Bony, S.: Influence of low cloud radiative effects on tropical circulation and precipitation, J. Adv. Model. Earth Syst., 6, 513-526, 2014.

Franklin, C. N., Sun, Z., Bi, D., Dix, M., Yan, H., and BodasSalcedo, A.: Evaluation of clouds in ACCESS using the satellite simulator package COSP: Global, seasonal, and regional cloud properties, J. Geophys. Res.-Atmos., 118, 732-748, doi:10.1029/2012JD018469, 2013.

Gates, W. L., Boyle, J. S., Covey, C., Dease, C. G., Doutriaux, C. M., Drach, R. S., Fiorino, M., Gleckler, P. J., Hnilo, J. J., Marlais, S. M., Phillips, T. J., Potter, G. L., Santer, B. D., Sperber, K. R., Taylor, K. E., and Williams, D. N.: An overview of the results of the Atmospheric Model Intercomparison Project (AMIP I), B. Am. Meteorol. Soc., 80, 29-55, 1999.

Geoffroy, O., Saint-Martin, D., Bellon, G., Voldoire, A., Olivié, D. J. L., and Tytéca, S.: Transient Climate Response in a Two-Layer Energy-Balance Model. Part II: Representation of the Efficacy of Deep-Ocean Heat Uptake and Validation for CMIP5 AOGCMs, J. Climate, 26, 1859-1876, 2013.

Good, P., Ingram, W., Lambert, F. H., Lowe, J. A., Gregory, J. M., Webb, M. J., Ringer, M. A., and Wu, P. L.: A step-response approach for predicting and understanding non-linear precipitation changes, Clim. Dynam., 39, 2789-2803, doi:10.1007/s00382012-1571-1, 2012.

Good, P., Lowe, J. A., Andrews, T., Wiltshire, A., Chadwick, R., Ridley, J. K., Menary, M. B., Bouttes, N., Dufresne, J. L., Gregory, J. M., Schaller, N., and Shiogama, H.: Nonlinear regional warming with increasing $\mathrm{CO}_{2}$ concentrations, Nat. Clim. Change, 5, 138-142, doi:10.1038/Nclimate2498, 2015.

Good, P., Andrews, T., Chadwick, R., Dufresne, J.-L., Gregory, J. M., Lowe, J. A., Schaller, N., and Shiogama, H.: nonlinMIP contribution to CMIP6: model intercomparison project for non-linear mechanisms: physical basis, experimental design and analysis principles (v1.0), Geosci. Model Dev., 9, 4019-4028, doi:10.5194/gmd-9-4019-2016, 2016.

Gordon, N. D. and Klein, S. A.: Low-cloud optical depth feedback in climate models, J. Geophys. Res.-Atmos., 119, 6052-6065, 2014.

Gregory, J. M. and Andrews, T.: Variation in climate sensitivity and feedback parameters during the historical period, Geophys. Res. Lett., 43, 3911-3920, doi:10.1002/2016GL068406, 2016.

Gregory, J. M. and Webb, M. J.: Tropospheric adjustment induces a cloud component in $\mathrm{CO}_{2}$ forcing, J. Climate, 21, 58-71, doi::10.1175/2007JCLI1834.1, 2008.

Gregory, J. M., Ingram, W. J., Palmer, M. A., Jones, G. S., Stott, P. A., Thorpe, R., Lowe, J. A., Johns, T. C., and Williams, K. D.: A new method for diagnosing radiative forcing and climate sensitivity, Geophys. Res. Lett, 31, L03205, doi:10.1029/2003GL018747, 2004.

Grise, K. M. and Polvani, L. M.: Southern hemisphere clouddynamics biases in CMIP5 models and their implications for climate projections, J. Climate, 27, 6074-6092, 2014.

Harries, J. E., Russell, J. E., Hanafin, J. A., Brindley, H., Futyan, J., Rufus, J., Kellock, S., Matthews, G., Wrigley, R., Last, A., Mueller, J., Mossavati, R., Ashmall, J., Sawyer, E., Parker, D., Caldwell, M., Allan, P. M., Smith, A., Bates, M. J., Coan, B.,
Stewart, B. C., Lepine, D. R., Cornwall, L. A., Corney, D. R., Ricketts, M. J., Drummond, D., Smart, D., Cutler, R., Dewitte, S., Clerbaux, N., Gonzalez, L., Ipe, A., Bertrand, C., Joukoff, A., Crommelynck, D., Nelms, N., Llewellyn-Jones, D. T., Butcher, G., Smith, G. L., Szewczyk, Z. P., Mlynczak, P. E., Slingo, A., Allan, R. P., and Ringer, M. A.: The geostationary earth radiation budget project, B. Am. Meteorol. Soc., 86, 945-960, 2005.

Harrop, B. E. and Hartmann, D. L.: The role of cloud radiative heating in determining the location of the ITCZ in aqua planet simulations, J. Climate, 29, 2741-2763, doi:10.1175/JCLI-D-150521.1, 2016.

Haynes, J. M., Marchand, R. T., Luo, Z., Bodas-Salcedo, A., and Stephens, G. L.: A multi-purpose radar simulation package: Quickbeam, B. Am. Meteorol. Soc., 88, 1723-1727, doi:10.1175/BAMS-88-11-1723, 2007.

Haynes, J. M., Vonder Haar, T. H., L'Ecuyer, T., and Henderson, D.: Radiative heating characteristics of earth's cloudy atmosphere from vertically resolved active sensors, Geophys. Res. Lett., 40, 624-630, doi:10.1002/grl.50145, 2013.

He, J. and Soden, B.: Anthropogenic weakening of the tropical circulation: The relative roles of direct $\mathrm{CO}_{2}$ forcing and sea surface temperature change, J. Climate, 28, 8728-8742, doi:10.1175/JCLI-D-15-0205.1, 2015.

He, J., Soden, B. J., and Kirtman, B.: The robustness of the atmospheric circulation and precipitation response to future anthropogenic surface warming, Geophys. Res. Lett., 41, 2614-2622, 2014.

Held, I. M. and Soden, B. J.: Robust responses of the hydrological cycle to global warming, J. Climate, 19, 5686-5699, 2006.

Huang, P., Xie, S. P., Hu, K., Huang, G., and Huang, R.: Patterns of the seasonal response of tropical rainfall to global warming, Nat. Geosci., 6, 357-361, 2013.

Hwang, Y. T. and Frierson, D.: Link between the doubleIntertropical Convergence Zone problem and cloud biases over the Southern, Proc. Natl. Acad. Sci. USA, 110, 4935-4940, 2013.

Jakob, C. and Tselioudis, G.: Objective identification of cloud regimes in the Tropical Western Pacific, Geophys. Res. Lett., 30, 2082, doi:10.1029/2003GL018367, 2003.

Jonko, A. K., Shell, K. M., Sanderson, B. M., and Danabasoglu, G.: Climate feedbacks in ccsm3 under changing $\mathrm{CO}_{2}$ forcing. Part ii: Variation of climate feedbacks and sensitivity with forcing, J. Climate, 26, 2784-2795, doi:10.1175/Jcli-D-12-00479.1, 2013.

Kageyama, M., Braconnot, P., Harrison, S. P., Haywood, A. M., Jungclaus, J., Otto-Bliesner, B. L., Peterschmitt, J.-Y., AbeOuchi, A., Albani, S., Bartlein, P. J., Brierley, C., Crucifix, M., Dolan, A., Fernandez-Donado, L., Fischer, H., Hopcroft, P. O., Ivanovic, R. F., Lambert, F., Lunt, D. J., Mahowald, N. M., Peltier, W. R., Phipps, S. J., Roche, D. M., Schmidt, G. A., Tarasov, L., Valdes, P. J., Zhang, Q., and Zhou, T.: PMIP4CMIP6: the contribution of the Paleoclimate Modelling Intercomparison Project to CMIP6, Geosci. Model Dev. Discuss., doi:10.5194/gmd-2016-106, in review, 2016.

Kamae, Y. and Watanabe, M.: On the robustness of tropospheric adjustment in CMIP5 models, Geophys. Res. Lett., 39, L23808, doi:10.1029/2012GL054275, 2012.

Kamae, Y. and Watanabe, M.: Tropospheric adjustment to increasing $\mathrm{CO}_{2}$ : its timescale and the role of land-sea contrast, Clim. Dynam., 41, 3007-3024, 2013. 
Kamae, Y., Watanabe, M., Kimoto, M., and Shiogama, H.: Summertime land-sea thermal contrast and atmospheric circulation over East Asia in a warming climate - Part II: Importance of $\mathrm{CO}_{2}$ induced continental warming, Clim. Dynam., 43, 2569-2583, 2014.

Kamae, Y., Watanabe, M., Ogura, T., Yoshimori, M., and Shiogama, H.: Rapid adjustments of cloud and hydrological cycle to increasing $\mathrm{CO}_{2}$ : A review, Curr. Clim. Change Rep., 1, 103-113, doi:10.1007/s40641-015-0007-5, 2015.

Kay, J. E., Hillman, B. R., Klein, S. A., Zhang, Y., Medeiros, B., Pincus, R., Gettelman, A., Eaton, B., Boyle, J., Marchand, R., and Ackerman, T. P.: Exposing global cloud biases in the Community Atmosphere Model (CAM) using satellite observations and their corresponding instrument simulators, J. Climate, 25, 5190-5207, doi:10.1175/JCLI-D-11-00469.1, 2012.

Kent, C., Chadwick, R., and Rowell, D. P.: Understanding uncertainties in future projections of seasonal tropical precipitation, J. Climate, 28, 4390-4413, 2015.

King, M. D., Menzel, W. P., Kaufman, Y. J., Tanre, D., Gao, B.-C., Platnick, S., Ackerman, S. A., Remer, L. A., Pincus, R., and Hubankset, P. A.: Cloud and aerosol properties, precipitable water, and profiles of temperature and humidity from MODIS, IEEE T. Geosci. Remote, 41, 442-458, doi:10.1109/TGRS.2002.808226, 2003.

Klein, S. A. and Jakob, C.: Validation and sensitivities of frontal clouds simulated by the ECMWF model, Mon. Weather Rev., 127, 2514-2531, 1999.

Klein, S. A., Zhang, Y., Zelinka, M. D., Pincus, R., Boyle, J., and Gleckler, P. J.: Are climate model simulations of clouds improving? An evaluation using the ISCCP simulator, J. Geophys. Res.Atmos., 118, 1329-1342, doi:10.1002/jgrd.50141, 2013.

Konsta, D., Chepfer, H., and Dufresne, J.-L.: A process oriented characterization of tropical oceanic clouds for climate model evaluation, based on a statistical analysis of daytime A-train observations, Clim. Dynam., 39, 2091-2108, doi:10.1007/s00382012-1533-7, 2012.

Konsta, D., Dufresne, J. L., Chepfer, H., Idelkali, A., and Cesana, G.: Use of A-train satellite observations (CALIPSO-PARASOL) to evaluate tropical cloud properties in the LMDZ5 GCM, Clim. Dynam., 47, 1263-1284, doi:10.1007/s00382-015-2900-y, 2015.

Lacagnina, C. and Selten, F.: Evaluation of clouds and radiative fluxes in the EC-Earth general circulation model, Clim. Dynam., 43, 2777-2796 doi:10.1007/s00382-014-2093-9, 2014.

Lacagnina, C., Selten, F., and Siebesma, A. P.: Impact of changes in the formulation of cloud-related processes on model biases and climate feedbacks, J. Adv. Model. Earth Syst., 6, 1224-1243, 2014.

Lambert, F. H. and Faull, N. E.: Tropospheric adjustment: the response of two general circulation models to a change in insolation, Geophys. Res. Lett., 34, L03802, doi:10.1029/2006GL028124, 2007.

L'Ecuyer, T. S. and McGarragh, G.: A 10-year climatology of tropical radiative heating and its vertical structure from TRMM observations, J. Climate, 23, 519-541, 2010.

Lee, M.-I., Kang, I.-S., Kim, J.-K., and Mapes, B. E.: Influence of cloud-radiation interaction on simulating tropical intraseasonal oscillation with an atmospheric general circulation model, J. Geophys. Res., 106, 14219-14233, 2001.
Li, Y., Thompson, D. W. J., and Bony, S.: The influence of cloud radiative effects on the large-scale atmospheric circulation, J. Climate, 28, 7263-7278, 2015.

Lin, J., Mapes, B., Zhang, M., and Newman, M.: Stratiform precipitation, vertical heating profiles, and the Madden-Julian Oscillation, J. Atmos. Sci., 61, 296-309, 2004.

Lin, J. L., Qian, T., and Shinoda, T.: Stratocumulus clouds in Southeastern Pacific simulated by eight CMIP5-CFMIP global climate models, J. Climate, 27, 3000-3022, 2014.

Loeb, N. G., Wang, H., Cheng, A., Kato, S., Fasullo, J. T., Xu, K.M., and Allan, R. P.: Observational constraints on atmospheric and oceanic cross-equatorial heat transports: revisiting the precipitation asymmetry problem in climate models, Clim. Dynam., 46, 3239-3257, doi:10.1007/s00382-015-2766-z, 2015.

Long, S. M., Xie, S. P., and Liu, W.: Uncertainty in tropical rainfall projections: Atmospheric circulation effect and the ocean coupling, J. Climate, doi:10.1175/JCLI-D-15-0601.1, online first, 2016.

Ma, J. and Xie, S. P.: Regional patterns of sea surface temperature change: A source of uncertainty in future projections of precipitation and atmospheric circulation, J. Climate, 26, 2482-2501, 2013.

Marchand, R. and Ackerman, T.: An analysis of cloud cover in multiscale modeling framework global climate model simulations using 4 and $1 \mathrm{~km}$ horizontal grids, J. Geophys. Res., 115, D16207, doi:10.1029/2009JD013423, 2010.

Marchand, R., Haynes, J., Mace, G. G., Ackerman, T., and Stephens, G.: A comparison of simulated cloud radar output from the multiscale modeling framework global climate model with CloudSat cloud radar observations, J. Geophys. Res., 114, D00A20, doi:10.1029/2008JD009790, 2009.

Marchand, R., Ackerman, T., Smyth, M., and Rossow, W. B.: A review of cloud top height and optical depth histograms from MISR, ISCCP, and MODIS, J. Geophys. Res., 115, D16206, doi:10.1029/2009JD013422, 2010.

Marchand, R. T., Alexander, S. P., and Protat, A.: Macquarie Island Cloud and Radiation Experiment (MICRE) Science Plan (No. DOE/SC-ARM-15-082), DOE ARM Climate Research Facility, Pacific Northwest National Laboratory; Richland, Washington, available at: http://www.arm.gov/publications/programdocs/ doe-sc-arm-15-082.pdf, 2015.

McAvaney, B. J. and Le Treut, H.: The cloud feedback intercomparison project: (CFMIP), in: CLIVAR Exchanges-supplementary contributions, 26 March 2003.

Medeiros, B., Stevens, B., Held, I. M., Zhao, M., Williamson, D. L., Olson, J. G., and Bretherton, C. S.: Aquaplanets, Climate Sensitivity, and Low Clouds, J. Climate, 21, 4974-4991, doi:10.1175/2008JCLI1995.1, 2008.

Medeiros, B., Stevens, B., and Bony, S.: Using aquaplanets to understand the robust responses of comprehensive climate models to forcing, Clim. Dynam., 44, 1957-1977, doi:10.1007/s00382014-2138-0, 2015.

Medeiros, B., Williamson, D. L., and Olson, J. G.: Reference aquaplanet climate in the community atmosphere model, version 5, J. Adv. Model. Earth Syst., 8, 40-424, doi:10.1002/2015MS000593, 2016.

Meraner, K., Mauritsen, T., and Voigt, A.: Robust increase in equilibrium climate sensitivity under global warming, Geophys. Res. Lett., 40, 5944-5948, 2013. 
Muller, C. and Bony, S.: What favors convective aggregation, and why?, Geophys. Res. Lett., 42, 5626-5634, doi:10.1002/2015GL064260, 2015.

Myers, T. A. and Norris, J. R.: Reducing the uncertainty in subtropical cloud feedback, Geophys. Res. Lett., 43, 2144-2148, doi:10.1002/2015GL067416, 2016.

Nam, C., Bony, S., Dufresne, J.-L., and Chepfer, H.: The "too few, too bright" tropical low-cloud problem in CMIP5 models, Geophys. Res. Lett., 39, L21801, doi:10.1029/2012GL053421, 2012.

Nam, C. C., Quaas, J., Neggers, R., Drian, S. L., and Isotta, F.: Evaluation of boundary layer cloud parameterizations in the ECHAM5 general circulation model using CALIPSO and CloudSat satellite data, J. Adv. Model. Earth Syst., 6, 300-314, doi:10.1002/2013MS000277, 2014.

Nam, C. C. W. and Quaas, J.: Geographically versus dynamically defined boundary layer cloud regimes and their use to evaluate general circulation model cloud parameterizations, Geophys. Res. Lett., 40, 4951-4956, doi:10.1002/grl.50945, 2013.

Neale, R. B. and Hoskins, B. J.: A standard test for AGCMs including their physical parametrizations: I: The proposal, Atmos. Sci. Lett., 1, 101-107, doi:10.1006/asle.2000.0022, 2000.

Neggers, R. A. J.: Attributing the behavior of low-level clouds in large scale models to subgrid scale parameterizations, J. Adv. Model. Earth Syst., 7, 2029-2043, doi:10.1002/2015MS000503, 2015.

Nuijens, L., Medeiros, B., Sandu, I., and Ahlgrimm, M.: The behavior of trade-wind cloudiness in observations and models: The major cloud components and their variability, J. Adv. Model. Earth Syst., 7, 600-616, 2015a.

Nuijens, L., Medeiros, B., Sandu, I.. and Ahlgrimm, M.: Observed and modeled patterns of covariability between low-level cloudiness and the structure of the trade-wind layer, J. Adv. Model. Earth Syst., 7, 1741-1764, 2015b.

Ogura, T., Webb, M. J., Watanabe, M., Lambert, F. H., Tsushima, Y., and Sekiguchi, M.: Importance of instantaneous radiative forcing for rapid tropospheric adjustment, Clim. Dynam., 43, 14091421, 2014.

Oueslati, B. and Bellon, G.: Tropical precipitation regimes and mechanisms of regime transitions: Contrasting two aquaplanet general circulation models, Clim. Dynam., 40, 2345-2358, 2013.

Oueslati, B., Bony, S., Risi, C., and Dufresne, J. L.: Interpreting the inter-model spread in regional precipitation projections in the tropics: role of surface evaporation and cloud radiative effects, Clim. Dynam., 47, 2801, doi:10.1007/s00382-016-2998-6, 2016.

Pendergrass, A. G. and Hartmann, D. L.: The atmospheric energy constraint on global-mean precipitation change, J. Climate, 27, 757-768, 2014.

Pincus, R., Platnick, S., Ackerman, S. A., Hemler, R. S., and Hofmann, P. R. J.: Reconciling simulated and observed views of clouds: MODIS, ISCCP, and the limits of instrument simulators, J. Climate, 25, 4699-4720, doi:10.1175/JCLI-D-1100267.1, 2012.

Pincus, R., Forster, P. M., and Stevens, B.: The Radiative Forcing Model Intercomparison Project (RFMIP): experimental protocol for CMIP6, Geosci. Model Dev., 9, 3447-3460, doi:10.5194/gmd-9-3447-2016, 2016.

Popke, D., Stevens, B., and Voigt, A.: Climate and climate change in a radiative-convective equilibrium version of ECHAM6, J. Adv. Model. Earth Syst., 5, 1-14, 2013.
Qu, X., Hall, A., Klein, S. A., and Caldwell, P. M.: On the spread of changes in marine low cloud cover in climate model simulations of the 21st century, Clim. Dynam., 42, 2603-2626, 2014.

Qu, X., Hall, A., Klein, S. A., and Caldwell, P. M.: The strength of the tropical inversion and its response to climate change in 18 CMIP5 models, Clim. Dynam., 45, 375-396, 2015.

Rädel, G., Mauritsen, T., Stevens, B., Dommenget, D., Matei, D., Bellomo, K., and Clement, A.: Amplification of El Niño by cloud longwave coupling to atmospheric circulation, Nat. Geosci., 9, 106-110, doi:10.1038/ngeo2630, 2016.

Randall, D. A., Dazlich, D. A., and Corsetti, T. G.: Interactions among radiation, convection, and large-scale dynamics in a general circulation model, J. Atmos. Sci., 46, 1943-1970, 1989.

Randall, D. A., Wood, R. A., Bony, S., Colman, R., Fichefet, T., Fyfe, J., Kattsov, V., Pitman, A., Shukla, J., Srinivasan, J., Stouffer, R. J., Sumi, A., and Taylor, K. E.: Climate models and their evaluation. In Climate Change 2007: The physical science basis. Contribution of Working Group I to the Fourth Assessment Report of the IPCC (FAR), Cambridge University Press, 589-662, 2007.

Rieck, M., Nuijens, L., and Stevens, B.: Marine Boundary Layer Cloud Feedbacks in a Constant Relative Humidity Atmosphere, J. Atmos. Sci., 69, 2538-2550, 2012.

Ringer, M. A., Andrews, T., and Webb, M. J.: Global-mean radiative feedbacks and forcing in atmosphere-only and fully-coupled climate change experiments, Geophys. Res. Lett., 41, 4035-4042, doi:10.1002/2014GL060347, 2014.

Rossow, W. B. and Schiffer, R. A.: Advances in understanding clouds from ISCCP, B. Am. Meteorol. Soc., 80, 2261-2287, 1999.

Santer, B. D., Painter, J. F., Bonfils, C., Mears, C. A., Solomon, S., Wigley, T. M., Gleckler, P. J., Schmidt, G. A., Doutriaux, C., Gillett, N. P., and Taylor, K. E.: Human and natural influences on the changing thermal structure of the atmosphere, P. Natl. Acad. Sci. USA, 110, 17235-17240, 2013.

Senior, C. A. and Mitchell, J. F. B.: The time-dependence of climate sensitivity, Geophys. Res. Lett., 21, 2685-2688, doi:10.1029/2000GL011373, 2000.

Shaw, T. A. and Voigt, A.: Tug of war on summertime circulation between radiative forcing and sea surface warming, Nat. Geosci., 8, 560-566, 2015.

Sherwood, S. C., Ramanathan, V., Barnett, T. P., Tyree, M. K., and Roeckner, E.: Response of an atmospheric general circulation model to radiative forcing of tropical clouds, J. Geophys. Res., 99, 20829-20845, 1994.

Sherwood, S. C., Bony, S., and Dufresne, J. L.: Spread in model climate sensitivity traced to atmospheric convective mixing, Nature, 505, 37-42, 2014.

Skinner, C. B., Ashfaq, M., and Diffenbaugh, N. S.: Influence of twenty-first-century atmospheric and sea surface temperature forcing on West African climate, J. Climate, 25, 527-542, 2012.

Slingo, A. and Slingo, J. M.: The response of a general circulation model to cloud longwave radiative forcing. I: Introduction and initial experiments, Q. J. Roy. Meteor. Soc., 114, 1027-1062, doi:10.1002/qj.49711448209, 1988.

Stevens, B. and Bony, S.: What Are Climate Models Missing?, Science, 340, 1053-1054, doi:10.1126/science.1237554, 2013.

Stevens, B., Bony, S., and Webb, M.: Clouds on-off Klimate intercomparison experiment (COOKIE), avail- 
able at: http://pubman.mpdl.mpg.de/pubman/item/escidoc: 2078839/component/escidoc:2079076/Cookie.pdf (last access: 14 December 2016), 2012.

Stevens, B., Farrell, D., Hirsch, L., Jansen, F., Nuijens, L., Serikov, I., Brügmann, B., Forde, M., Linne, H., Lonitz, K., and Prospero, J. M.: The Barbados Cloud Observatory-Anchoring Investigations of Clouds and Circulation on the Edge of the ITCZ, B. Am. Meteorol. Soc., doi:10.1175/BAMS-D-14-00247.1, online first, 2015.

Stratton, R. A. and Stirling, A. J.: Improving the diurnal cycle of convection in GCMs, Q. J. Roy. Meteor. Soc., 138, 1121-1134, doi:10.1002/qj.991, 2011.

Su, H., Jiang, J. H., Zhai, C., Shen, T. J., Neelin, J. D., Stephens, G. L., and Yung, Y. L.: Weakening and strengthening structures in the Hadley Circulation change under global warming and implications for cloud response and climate sensitivity, J. Geophys. Res.-Atmos., 119, 5787-5805, 2014.

Taylor, K. E., Stouffer, R. J., and Meehl, G. A.: An overview of CMIP5 and the experiment design, B. Am. Meteorol. Soc., 93, 485-498, 2012.

Teixeira, J., Waliser, D., Ferraro, R., Gleckler, P., Lee, T., and Potter, G.: Satellite observations for CMIP5: the genesis of Obs4MIPs, B. Am. Meteorol. Soc., 95, 1329-1334, doi:10.1175/BAMS-D12-00204.1, 2014.

Tsushima, Y., Ringer, M. A., Webb, M. J., and Williams, K. D.: Quantitative evaluation of the seasonal variations in climate model cloud regimes, Clim. Dynam., 41, 2679-2696, doi:10.1007/s00382-012-1609-4, 2013.

Tsushima, Y., Ringer, M. A., Koshiro, T., Kawai, H., Roehrig, R., Cole, J., Watanabe, M., Yokohata, T., Bodas-Salcedo, A., Williams, K. D., and Webb, M. J.: Robustness, uncertainties, and emergent constraints in the radiative responses of stratocumulus cloud regimes to future warming, Clim. Dynam., 46, 3025, doi:10.1007/s00382-015-2750-7, 2016.

Vial, J., Dufresne, J.-L., and Bony, S.: On the interpretation of intermodel spread in CMIP5 climate sensitivity estimates, Clim. Dynam., 41, 3339-3362, doi:10.1007/s00382-013-1725-9, 2013.

Voigt, A. and Shaw, T. A.: Circulation response to warming shaped by radiative changes of clouds and water vapour, Nat. Geosci., 8 , 102-106, doi:10.1038/ngeo2345, 2015.

Voigt, A., Bony, S., Dufresne, J.-L., and Stevens, B.: The radiative impact of clouds on the shift of the inter-tropical convergence zone, Geophys. Res. Lett., 41, 4308-4315, doi:10.1002/2014GL060354, 2014.

Webb, M., Senior, C., Bony, S., and Morcrette, J. J.: Combining ERBE and ISCCP data to assess clouds in the Hadley Centre, ECMWF and LMD atmospheric climate models, Clim. Dynam., 17, 905-922, 2001.

Webb, M. J. and Lock, A. P.: Coupling between subtropical cloud feedback and the local hydrological cycle in a climate model, Clim. Dynam., 41, 1923-1939, 2013.

Webb, M. J., Senior, C. A., Sexton, D. M. H., Ingram, W. J., Williams, K. D., Ringer, M. A., McAvaney, B. J., Colman, R., Soden, B. J., Gudgel, R., Knutson, T., Emori, S., Ogura, T., Tsushima, Y., Andronova, N., Li, B., Musat, I., Bony, S., and Taylor, K. E.: On the contribution of local feedback mechanisms to the range of climate sensitivity in two GCM ensembles, Clim. Dynam., 27, 17-38, 2006.
Webb, M. J., Lock, A. P., Bodas-Salcedo, A., Bony, S., Cole, J. N. S., Koshiro, T., Kawai, H., Lacagnina, C., Selten, F. M., Roehrig, R., and Stevens, B.: The diurnal cycle of marine cloud feedback in climate models, Clim. Dynam., 44.5-6, 1419-1436, 2015a.

Webb, M. J., Lock, A. P., Bretherton, C. S., Bony, S., Cole, J. N. S., Idelkadi, A., Kang, S. M., Koshiro, T., Kawai, H., Ogura, T., Roehrig, R., Shin, Y., Mauritsen, T., Sherwood, S. C., Vial, J., Watanabe, M., Woelfle, M. D., and Zhao, M.: The impact of parametrized convection on cloud feedback, Philos. Tr. R. Soc. A, 373, 20140414, doi:10.1098/rsta.2014.0414, 2015 b.

Widlansky, M. J., Timmermann, A., Stein, K., McGregor, S., Schneider, N., England, M. H., Lengaigne, M., and Cai, W.: Changes in South Pacific rainfall bands in a warming climate, Nat. Clim. Change, 3, 417-423, 2013.

Williams, K. D. and Webb, M. J.: A quantitative performance assessment of cloud regimes in climate models, Clim. Dynam., 33, 141-157, 2009.

Williams, K. D., Ingram, W. J., and Gregory, J. M.: Time variation of effective climate sensitivity in GCMs, J. Climate, 21, 50765090, 2008.

Williams, K. D., Bodas-Salcedo, A., Déqué, M., Fermepin, S., Medeiros, B., Watanabe, M., Jakob, C., Klein, S., Senior, C. A., and Williamson, D. L.: The Transpose-AMIP II experiment and its application to the understanding of Southern Ocean cloud biases in climate models, J. Climate, 26, 3258-3274, doi:10.1175/JCLI-D-12-00429.1, 2013.

Williams, K. D., Harris, C. M., Bodas-Salcedo, A., Camp, J., Comer, R. E., Copsey, D., Fereday, D., Graham, T., Hill, R., Hinton, T., Hyder, P., Ineson, S., Masato, G., Milton, S. F., Roberts, M. J., Rowell, D. P., Sanchez, C., Shelly, A., Sinha, B., Walters, D. N., West, A., Woollings, T., and Xavier, P. K.: The Met Office Global Coupled model 2.0 (GC2) configuration, Geosci. Model Dev., 8, 1509-1524, doi:10.5194/gmd-8-1509-2015, 2015.

Williamson, D. L., Blackburn, M. Hoskins, B. J., Nakajima, K., Ohfuchi, W., Takahashi, Y. O., Hayashi, Y.-Y., Nakamura, H., Ishiwatari, M., McGregor, J. L., Borth, H., Wirth, V., Frank, H., Bechtold, P., Wedi, N. P., Tomita, H., Satoh, M., Zhao, M., Held, I. M., Suarez, M. J., Lee, M.-I., Watanabe, M., Kimoto, M., Liu, Y., Wang, Z., Molod, A., Rajendran, K., Kitoh, A., and Stratton, R.: The APE Atlas. NCAR Technical Note NCAR/TN- 484+STR, National Center for Atmospheric Research, doi:10.5065/D6FF3QBR, 2012.

Wood, R., Wyant, M., Bretherton, C. S., Rémillard, J., Kollias, P., Fletcher, J., Stemmler, J., De Szoeke, S., Yuter, S., Miller, M., and Mechem, D.: Clouds, aerosols, and precipitation in the marine boundary layer: an ARM mobile facility deployment, B. Am. Meteorol. Soc., 96, 419-440, 2015.

Wyant, M. C., Bretherton, C. S., Blossey, P. N., and Khairoutdinov, M.: Fast cloud adjustment to increasing $\mathrm{CO}_{2}$ in a superparameterized climate model, J. Adv. Model. Earth Syst., 4, M05001, doi:10.1029/2011MS000092, 2012.

Xavier, P. K., Petch, J. C., Klingaman, N. P., Woolnough, S. J., Jiang, X., Waliser, D. E., Caian, M., Cole, J., Hagos, S. M., Hannay, C., and Kim, D.: Vertical structure and physical processes of the Madden-Julian Oscillation: Biases and uncertainties at short range, J. Geophys. Res.-Atmos., 120, 4749-4763, 2015.

Yang, G.-Y. and Slingo, J.: The diurnal cycle in the tropics, Mon. Weather Rev., 129, 784-801, 2001. 
Yoshimori, M., Yokohata, T., and Abe-Ouchi, A.: A comparison of climate feedback strength between $\mathrm{CO}_{2}$ doubling and LGM experiments, J. Climate, 22, 3374-3395, 2009.

Yoshimori, M., Watanabe, M., Abe-Ouchi, A., Shiogama, H., and Ogura, T.: Relative contribution of feedback processes to Arctic amplification of temperature change in MIROC GCM, Clim. Dynam., 42, 1613-1630, 2014.

Yu, W., Doutriaux, M., Sèze, G., Le Treut, H., and Desbois, M.: A methodology study of the validation of clouds in GCMs using ISCCP satellite observations, Clim. Dynam., 12, 389-401,1996.

Yuan, T., Oreopoulos, L., Zelinka, M., Yu, H., Norris, J. R., Chin, M., Platnick, S., and Meyer, K.: Positive low cloud and dust feedbacks amplify tropical North Atlantic Multidecadal Oscillation, Geophys. Res. Lett., 43, 1349-1356, doi:10.1002/2016GL067679, 2016.

Zelinka, M. D., Klein, S. A., and Hartmann, D. L.: Computing and Partitioning Cloud Feedbacks Using Cloud Property Histograms. Part I: Cloud Radiative Kernels, J. Climate, 25, 37153735, doi:10.1175/JCLI-D-11-00248.1, 2012a.

Zelinka, M. D., Klein, S. A., and Hartmann, D. L.: Computing and Partitioning Cloud Feedbacks Using Cloud Property Histograms. Part II: Attribution to Changes in Cloud Amount, Altitude, and Optical Depth, J. Climate, 25, 3736-3754, doi:10.1175/JCLI-D11-00249, 2012b.

Zelinka, M. D., Klein, S. A., Taylor, K. E., Andrews, T., Webb, M. J., Gregory, J. M., and Forster, P. M.: Contributions of Different Cloud Types to Feedbacks and Rapid Adjustments in CMIP5, J. Climate., 26, 5007-5027, doi:10.1175/JCLI-D-12$00555.1,2013$.
Zelinka, M. D., Andrews, T., Forster, P. M., and Taylor, K. E.: Quantifying components of aerosol-cloud-radiation interactions in climate models, J. Geophys. Res.-Atmos., 119, 7599-7615, doi:10.1002/2014JD021710, 2014.

Zhang, Y., Klein, S. A., Boyle, J., and Mace, G. G.: Evaluation of tropical cloud and precipitation statistics of CAM3 using CloudSat and CALIPSO data, J. Geophys. Res., 115, D12205, doi:10.1029/2009JD012006, 2010.

Zhang, M., Bretherton, C. S., Blossey, P. N., Austin, P. H., Bacmeister, J. T., Bony, S., Brient, F., Cheedela, S. K., Cheng, A., Genio, A. D., and Roode, S. R.: CGILS: Results from the first phase of an international project to understand the physical mechanisms of low cloud feedbacks in single column models, J. Adv. Model. Earth Syst., 5, 826-842, 2013.

Zhao, M.: An investigation of the connections among convection, clouds, and climate sensitivity in a global climate model, J. Climate, 27, 1845-1862, doi:10.1175/JCLI-D-13-00145.1, 2014.

Zhou, Z. Q., Xie, S. P., Zheng, X. T., Liu, Q., and Wang, H.: Global warming-induced changes in El Niño teleconnections over the North Pacific and North America, J. Climate, 27, 9050-9064, 2014.

Zurovac-Jevtic, D., Bony, S., and Emanuel, K. A.: On the role of clouds and moisture in tropical waves: a two-dimensional model study, J. Atmos. Sci., 63, 2140-2155, 2006. 